\title{
Adult Neurogenesis and Mental Illness
}

\author{
Timothy J Schoenfeld ${ }^{1}$ and Heather A Cameron ${ }^{\star 1}$ \\ ${ }^{1}$ Section on Neuroplasticity, National Institute of Mental Health, National Institutes of Health, Bethesda, MD, USA
}

\begin{abstract}
Several lines of evidence suggest that adult neurogenesis, the production of new neurons in adulthood, may play a role in psychiatric disorders, including depression, anxiety, and schizophrenia. Medications and other treatments for mental disorders often promote the proliferation of new neurons; the time course for maturation and integration of new neurons in circuitry parallels the delayed efficacy of psychiatric therapies; adverse and beneficial experiences similarly affect development of mental illness and neurogenesis; and ablation of new neurons in adulthood alters the behavioral impact of drugs in animal models. At present, the links between adult neurogenesis and depression seem stronger than those suggesting a relationship between new neurons and anxiety or schizophrenia. Yet, even in the case of depression there is currently no direct evidence for a causative role. This article reviews the data relating adult neurogenesis to mental illness and discusses where research needs to head in the future.
\end{abstract}

Neuropsychopharmacology Reviews (2015) 40, II3-128; doi: I0.1038/npp.2014.230; published online 24 September 2014

\section{INTRODUCTION}

Mental illness is debilitating not only to those afflicted with various disorders but to mankind as a whole. It has been estimated that $26 \%$ of the adult population have a diagnosable mental disorder (Kessler et al, 2005), and the economic burden of serious mental illness yearly has been estimated at 193 billion dollars because of annual loss of earnings alone (Kessler et al, 2008). More effective and innovative treatment options are necessary for battling this terrible burden.

The hippocampus has long been associated with psychiatric disorders (Antonova et al, 2004; Geuze et al, 2005; Sapolsky, 2000). The hippocampus is highly plastic throughout life and is particularly sensitive to changes in the environment, making it a promising research target for mental illness. Developmental lesions of the ventral hippocampus produce an animal model of schizophrenia (Lipska et al, 2002; Swerdlow et al, 2001). Hippocampal volume reductions are reported in patients suffering from various mental disorders such as depression, anxiety, and schizophrenia (Campbell et al, 2004; Nelson et al, 1998; Sheline et al, 2003; Vythilingam et al, 2002), as well as in animal models of these diseases (Gilabert-Juan et al, 2013; Golub et al, 2011; Kaae et al, 2012; Kalisch et al, 2006). Understanding how the hippocampus is changed in the

${ }^{*}$ Correspondence: $\mathrm{Dr} \mathrm{H}$ Cameron, Section on Neuroplasticity, $\mathrm{NIMH}$, 35 Convent Drive, Building 35/3C915, Bethesda, MD 20892-3718, USA, Tel: +1 301496 3814, Fax: +1 301480 4564,

E-mail: heathercameron@mail.nih.gov

Received 11 April 2014; revised 28 August 2014; accepted 28 August 2014; accepted article preview online 2 September 2014 context of mental disorders will provide clues to their etiology and new avenues for prevention and treatment of these diseases.

One unusual feature of the hippocampus is that it contains a population of neuronal precursor cells in the dentate gyrus that generate large numbers of new granule neurons throughout adulthood. The mechanisms, stages, and time course of adult neurogenesis in the dentate gyrus have been extensively studied (Aimone et al, 2014; Lepousez et al, 2013). New dentate gyrus neurons generate action potentials (van Praag et al, 2002) and are activated by functionally relevant experiences (Belarbi et al, 2012; Kee et al, 2007; Schoenfeld et al, 2013; Snyder et al, 2009a, 2009c, 2012; Tashiro et al, 2007), suggesting that new neurons play a role in functions associated with this region.

The generation of new neurons in the adult brain has been of particular interest to researchers investigating the etiology and treatment of mental illness (Eisch, 2002; Jacobs et al, 2000; Lucassen et al, 2009; Samuels and Hen, 2011a), because of a number of similarities between the factors regulating adult neurogenesis and affecting psychiatric disease. Evidence that new neurons are important for mental health could come from: (1) factors that trigger or increase likelihood of developing mental illness and inhibit neurogenesis; (2) drugs and other treatments that improve mental illness or its symptoms and enhance neurogenesis; (3) behavioral changes mimicking features of illness that occur following inhibition of adult neurogenesis in animals; and (4) changes in adult neurogenesis in patients with disease. In this review, we will discuss each of these types of evidence, focusing on the potential links between adult neurogenesis and major depression, anxiety disorders, and schizophrenia. 


\section{GENETIC AND ENVIRONMENTAL EFFECTS ON ADULT NEUROGENESIS AND MENTAL ILLNESS}

One argument for a role of new neurons in the adult mammalian brain in positive mental health is that a number of behaviors and experiences that affect mental health also alter adult neurogenesis (Eisch, 2002; Jacobs et al, 2000; Lucassen et al, 2009; Samuels and Hen, 2011a). Typically, negative experiences, such as stress, sleep deprivation, and inflammation, adversely affect mental health and decrease the generation of new neurons. Conversely, positive experiences, such as exercise and environmental enrichment, tend to have beneficial effects on mental health and increase adult neurogenesis. Genetic predispositions and developmental insults also tend to affect adult neurogenesis and development of mental illness in parallel.

\section{Effects of Early-Life Experiences on Adult Neurogenesis and Mental IIIness}

There is growing interest in the long-lasting effects of childhood trauma on mental health into adulthood. Among the general population, people with a history of childhood trauma, including physical, emotional, and/or sexual abuse, are predisposed to anxiety and depression (Chapman et al, 2004; McCauley et al, 1997; Moffitt et al, 2007). Adults who have had hallucinations are also more likely to have suffered from childhood physical or sexual abuse (Whitfield et al, 2005). In patients with diagnosed schizophrenia, there is also a positive association between childhood abuse and specifically dissociative symptoms in adulthood (Holowka et al, 2003; Sar et al, 2010; Schäfer et al, 2012). In addition, traumatic events not involving abuse, such as parental loss early in life, are associated with developing major depression, anxiety disorders, and schizophrenia in adulthood (Agid et al, 1999; Kendler et al, 1992). Even prenatal stress, because of infection, malnutrition, or maternal psychological stress, is a significant risk factor for developing mental illness in adulthood (Brown et al, 2000, 2004; St Clair et al, 2005; Stein et al, 2009; Watson et al, 1999). In women with major depression, childhood abuse is correlated with smaller hippocampal volume, suggesting long-lasting effects of developmental experience on hippocampal structure in humans (Vythilingam et al, 2002).

In animal models, early-life stress increases behavior suggestive of psychiatric illness in adulthood. Rodents born to mothers experiencing stress during pregnancy show behavioral deficits thought to model depression, anxiety, and schizophrenia. Maternal infection, stress, and malnutrition increase schizophrenia-like behavior in adult offspring (Borrell et al, 2002; Fortier et al, 2007; Koenig et al, 2005; Palmer et al, 2004). Elevated anxiety-like behavior is seen in mice and rats exposed to prenatal infection and stress (Enayati et al, 2012; Fride and Weinstock, 1988; Hava et al, 2006; Walf and Frye, 2007). Prenatal infections and stress also increase depression-like behavior in adult rodents (Abe et al, 2007; Enayati et al, 2012; Lin and Wang, 2014; Tamura et al, 2011). During the early postnatal period, maternal separation, a commonly used experimental early-life stress, leads to increased anxiety-, depression-, and schizophrenialike behavior in adulthood (Chen et al, 2011; Ellenbroek et al, 1998; Huot et al, 2001; Martisova et al, 2012; Romeo et al, 2003). In addition, juvenile rodents exposed to stressful events after weaning show increased depressionand anxiety-like behavior in adulthood (Jacobson-Pick and Richter-Levin, 2010; Pohl et al, 2007; Wilkin et al, 2012).

Early-life stress typically inhibits the production of new neurons in adulthood. Prenatal stress produces long-lasting deficits in the production and survival of new neurons into adulthood (Koo et al, 2003; Lemaire et al, 2000; Zuena et al, 2008). A recent study indicates that infection during pregnancy reduces cell proliferation and neurogenesis in both juvenile and adult offspring (Lin and Wang, 2014). Undernourished mothers produce offspring with lower rates of cell proliferation and neuronal survival in adulthood (Matos et al, 2011). Prenatal stress and maternal separation even decreases the size and complexity of the new neurons that are born in adulthood in the dentate gyrus (Leslie et al, 2011; Tamura et al, 2011). Stress during the early postnatal period produced by maternal separation reduces cell proliferation, neurogenesis, and the survival of new neurons in adult rodents in the dentate gyrus (Aisa et al, 2009; Leslie et al, 2011; Mirescu et al, 2004; Sachs et al, 2013).

The evidence that enriching experiences during early life lead to positive effects on adult mental health and neurogenesis in the dentate gyrus is more mixed. One study reported that housing pregnant dams in an enriched environment led to decreased anxiety-like behavior in adult offspring (Friske and Gammie, 2005). However, environmental enrichment for neonates and juvenile rodents had anxiolytic- and antidepressant-like effects on adult behavior in some studies (Baldini et al, 2013; Benaroya-Milshtein et al, 2004; Urakawa et al, 2013; Workman et al, 2011) but not others (Ishihama et al, 2010; Workman et al, 2011; Yildirim et al, 2012). Early-life wheel running also appears to have little effect on adult anxiety-like behavior (Ishikawa et al, 2014). Evidence is similarly sparse and mixed on lasting effects of early-life and prenatal enrichment on adult neurogenesis (Boehme et al, 2011; Schaefers, 2013). Given that the effects of early-life enrichment on neurogenesis and behavior are similarly mixed, this might still indicate parallels. It may be that animal models of environmental enrichment, which were developed for adult animals, are simply not as enriching for juveniles or pregnant dams. It is also possible that standard experimental housing, with plenty of food and an absence of predators, provide an optimal environment for emotional/cognitive development of rodents. In any case, it is unclear from animal studies whether positive events, or simply the lack of negative events, during development affect neurogenesis and behavior into adulthood. However, the data make a strong case that adverse experiences in early development can inhibit 
neurogenesis and increase mental illness-related behaviors in adulthood.

\section{Adverse Experiences in Adulthood}

Stressful experiences have long been linked as potential contributors to the development of psychiatric disorders (Anisman and Zacharko, 1982; Kessler et al, 1985). Prolonged stress in humans can lead to an overloading of the stress response system, leaving people at risk for the development of illness, both physical and psychiatric (McEwen, 2004). Chronic exposure to stress has been implicated as a predisposing factor for developing major depressive disorder, anxiety disorders, posttraumatic stress disorder, and schizophrenia (Davidson and Baum, 1986; Gold et al, 1988; Pêgo et al, 2010; Pollin, 1972; Southwick et al, 2005). Chronic stress is frequently used in animals to produce behavioral states modeling depression, anxiety, and schizophrenia (Bahi, 2013; Brzózka et al, 2011; Katz, 1982; Taliaz et al, 2011). The hippocampus is a key brain region for linking stress and behavior. Hippocampal neurons express high levels of glucocorticoid and mineralocorticoid receptors, receptors for stress hormones, and the hippocampus provides negative feedback of the stress response, inhibiting the hypothalamic-pituitary-adrenal (HPA) axis in response to an increase in circulating stress hormones (Gerlach and McEwen, 1972; Jankord and Herman, 2008; McEwen et al, 1968; Roozendaal et al, 2001). New neurons in the adult dentate gyrus have receptors for stress hormones and are activated by stress, and hence they could play a direct role in stress response (Cameron et al, 1993; Schoenfeld and Gould, 2013). The effects of stress on adult neurogenesis are complex (reviewed in Schoenfeld and Gould, 2012), but it is clear that in at least some situations, chronic stress can reduce cell proliferation and survival of new neurons in the dentate gyrus (Czéh et al, 2007; Dagyte et al, 2009; Ferragud et al, 2010; Pham et al, 2003).

Prolonged sleep deprivation has been suggested to be a risk factor for developing mood disorders like depression and anxiety disorders (Kahn-Greene et al, 2007; Taylor et al, 2005; Tkachenko et al, 2014), and patients with schizophrenia show impairments in various stages of sleep (Ferrarelli et al, 2010; Keshavan et al, 1998). Similarly, in animal studies, sleep deprivation can increase anxiety-like behavior in mice (Silva et al, 2004), and rodent models of anxiety, depression, and schizophrenia produce fragmented sleep (Grønli et al, 2004; Jakubcakova et al, 2012; Oliver et al, 2012; Phillips et al, 2012; Popa et al, 2006). The production of new neurons in the dentate gyrus is also inhibited by chronic sleep restriction or fragmentation (Mirescu et al, 2006).

A proinflammatory state has been associated with mental disorders, including major depression, anxiety, and schizophrenia (Dowlati et al, 2010; Fan et al, 2007; Rohleder et al, 2004). Increased inflammation has been suggested as a risk factor for developing a mood or psychotic disorder (Pervanidou et al, 2007; Reichenberg et al, 2001; Stojanovic et al, 2014; Wichers et al, 2007), and anti-inflammatory medication reduces symptoms of depression in antidepressant-resistant populations (Raison et al, 2012). In rodents, activating inflammation in the brain, by genetic means or injection of endotoxins, induces behavioral phenotypes of depression, anxiety, and schizophrenia (Fahey et al, 2007; Takao et al, 2013; Wohleb et al, 2011), and suppresses proliferation and survival of new neurons in the dentate gyrus (Ekdahl et al, 2003; Goshen et al, 2007; Monje et al, 2003; Vallières et al, 2002).

\section{Effects of Rewarding Experiences on Adult Neurogenesis and Mental IIIness}

Physical exercise can reduce symptoms in patients suffering from major depression, anxiety disorders, and schizophrenia (Beebe et al, 2005; Blumenthal et al, 1999; Herring et al, 2011), and can reduce feelings of anxiety and depression in healthy adults as well (Blumenthal et al, 1982; DiLorenzo et al, 1999). Similarly, exercise in the form of voluntary wheel running also ameliorates depressive- and anxiety-like symptoms in naive animals (Duman et al, 2008; Schoenfeld et al, 2013) as well as in animal models of mental illness (Lapmanee et al, 2013; Maniam and Morris, 2010; Wolf et al, 2011). Wheel running robustly enhances adult neurogenesis in experimental animals, increasing the proliferation, maturation, and survival of new neurons in the dentate gyrus (Schoenfeld et al, 2013; Snyder et al, 2009b; Stranahan et al, 2006; van Praag et al, 1999).

Another experimental manipulation used to bolster the proliferation and survival of new neurons in the adult dentate gyrus is enrichment of the animals' housing environment through the addition of toys, tunnels, greater space, social interactions, and other means to make home cages more complicated and stimulating (Kempermann et al, 1997; van Praag et al, 1999; Veena et al, 2009a). These environmental enrichments also reduce anxiety-, depressive-, and schizophrenic-related behaviors in animal models of illness (Jha et al, 2011; McOmish et al, 2008; Veena et al, 2009b). The effects of housing environments on adult neurogenesis and behavior in animals may parallel environmental effects on mental illness in humans, although it is unclear exactly what type of experience is modeled by enrichment of rodent cages. One possibility is that impoverished standard rodent cage environments model low socioeconomic status (Milgram et al, 2006). It has long been thought that socioeconomic status contributes to mental health, with higher prevalence of depression, anxiety, and schizophrenia in lower-income populations (Hemmingsson, 2014; Holzer et al, 1986; Kessler et al, 1994; Zimmerman and Katon, 2005). The specific environmental features responsible for the risk are difficult to delineate, however. For example, one factor that has been a focus of attention in human studies, income inequality (Pickett and Wilkinson, 2010), is unlikely to apply directly to rodent-enriched environment models, but dominant and subordinate 
rodents may have unequal access to preferred toys or shelters in enriched environments.

\section{EFFECTS OF PSYCHIATRIC MEDICATIONS AND TREATMENTS ON ADULT NEUROGENESIS}

In addition to looking for parallels between factors that regulate neurogenesis and those that predispose humans to psychiatric disorders, a great deal of work has investigated the relationship between neurogenesis and treatments for mental illness (Figure 1). Demonstrating an effect of a psychiatric medication on neurogenesis provides intriguing but relatively weak evidence for a link between new neurons and disease, but the finding that drugs with different direct targets and nonpharmacological treatments have similar neurogenic effects begins to make a stronger, if still indirect, case for a causative connection.

\section{Depression}

The past decade and a half of research on the role of adult neurogenesis in mental disorders has focused mainly on depression. The neurogenesis hypothesis of depression (Duman et al, 1999; Madsen et al, 2000; Sahay and Hen, 2007; Sapolsky, 2000) postulates that the production of new neurons may be causally related to depressive behaviors, based primarily on findings that stress inhibits adult neurogenesis and increases vulnerability to depression, that the time course of the differentiation, maturation, and integration of new neurons into dentate gyrus circuitry parallels the timing of antidepressant efficacy, and that antidepressant treatments increase the rate of adult neurogenesis in the dentate gyrus (Duman et al, 1999; Madsen et al, 2000).

Many classical antidepressant drugs and therapeutic interventions have positive effects on the rates of cell proliferation and neurogenesis in the dentate gyrus of adult mammals. This was demonstrated first by showing that electroconvulsive shock treatment, a clinically effective tool to treat major depression, increased neurogenesis in adult rodents (Madsen et al, 2000; Scott et al, 2000), an experiment likely inspired by earlier findings that chemical and electrically induced seizures increase granule cell precursor proliferation (Bengzon et al, 1997; Parent et al, 1997). Malberg et al (2000) significantly extended this finding, demonstrating that chronic treatment with classic antidepressants fluoxetine, reboxetine, and tranylcypromine, as well as electroconvulsive shock, increased neurogenesis in the adult rodent. This research importantly showed that different antidepressants that target different neurotransmitters, that is, serotonin and norepinephrine, have the same effect on adult neurogenesis (Malberg et al, 2000). Chronic fluoxetine and electroconvulsive shock also increase adult neurogenesis in non-human primates (Perera et al, 2007, 2011). Additional studies have since shown that additional SSRIs (citalopram and escitalopram), tricyclics (imipramine), and mood stabilizers (lithium) all enhance

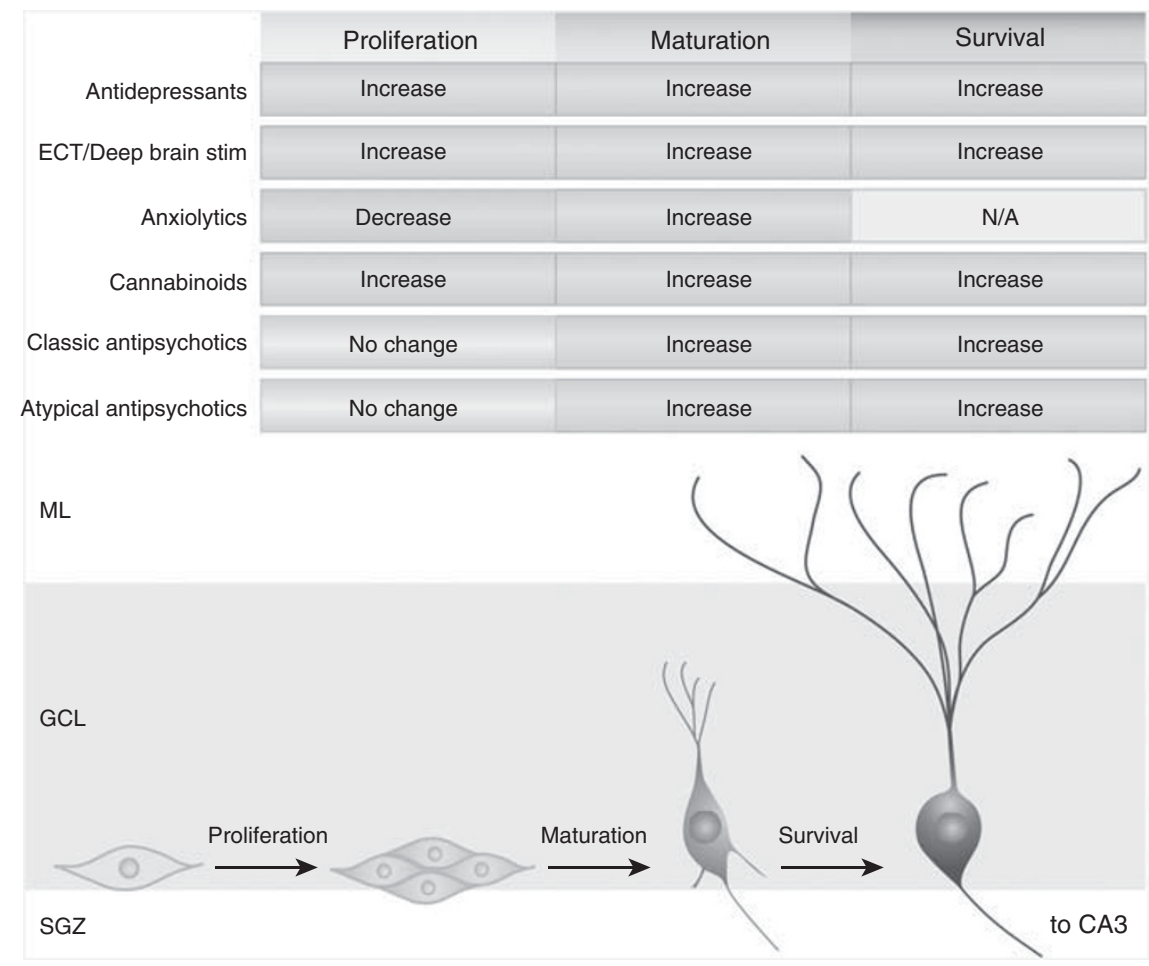

Figure 1. Summary of the effects of psychiatric drugs and other therapies on different processes involved in neurogenesis. The processes, shown below, include division of stem and precursor cells to generate additional neuronal progenitors (proliferation), development of neuronal morphology and functional synapses (maturation), and avoidance of cell death that normally eliminates a large fraction of new neurons (survival). 
cell proliferation and neurogenesis in the adult rodent (Chen et al, 2000; Jaako-Movits et al, 2006; Jayatissa et al, 2006; Surget et al, 2008). Atypical antidepressants, such as AMPA-receptor potentiators, agomelatine, and other 5HT$2 \mathrm{C}$ antagonists, increase production of new neurons in the rodent as well (Bai et al, 2003; Banasr et al, 2006; Dekeyne et al, 2008; Soumier et al, 2009). Similarly, transcranial magnetic stimulation, like ECS, increases proliferation of granule cell precursors (Zhang et al, 2014). Acute, but not chronic (see above), sleep deprivation also rapidly increases granule cell precursor proliferation and improves symptoms of depression (Grassi Zucconi et al, 2006), although the speed of these behavioral changes make it unlikely that they are related to the birth of the still very immature neurons.

Most studies of antidepressant treatment on adult neurogenesis have focused on changes in proliferation, but recent findings indicate that antidepressants can alter maturation and survival of new neurons as well. Chronic fluoxetine treatment hastens maturation of new neurons and enhances LTP of new neurons (Wang et al, 2008). Agomelatine increases survival of new neurons and enhances their maturation, as seen by their more rapid loss of the immature marker PSA-NCAM (Soumier et al, 2009). Electroconvulsive shock, deep brain stimulation, and transcranial magnetic stimulation also hasten new neuron maturation, enhancing dendritic growth and inducing mature spine formation in newly born neurons and increasing their survival (Schmuckermair et al, 2013; Zhang et al, 2014; Zhao et al, 2012).

The slow time course of maturation and integration of new neurons into dentate gyrus circuitry was also part of the initial rationale for the neurogenesis hypothesis of depression, as the well-accepted delay in therapeutic onset of antidepressants suggests that some neuroplastic change is required. There is typically a delay of at least 2 weeks between the start of antidepressant treatment and positive effects on depressive behavior (Bodnoff et al, 1988; Duman et al, 1997; Porsolt et al, 1978; Wang et al, 2008; Willner et al, 1987). It also requires at least 2-3 weeks for granule cells in the rodent dentate gyrus to become functionally integrated into existing circuitry, showing electrophysiological activation and behavioral relevance (Schmidt-Hieber et al, 2004; Shors et al, 2001; Snyder et al, 2005, 2009a). Other studies have suggested a somewhat longer time course of new neuron maturation (Denny et al, 2012; Espósito et al, 2005; Ge et al, 2007; Gu et al, 2012; Kee et al, 2007; van Praag et al, 2002; Zhao et al, 2006), a difference that may reflect different methods of assessing integration and functionality (eg, physiogical profiles of neurons $v s$ behavioral effects), species differences between mice and rats (Snyder et al, 2009a), and differential housing or other environmental conditions, such as running, that affect the time course of new neuron maturation (Piatti et al, 2011; Snyder et al, 2009b). Altogether, rodent studies suggest that new neurons require between 1 and 8 weeks to become mature.
The novel antidepressant ketamine has recently demonstrated very rapid therapeutic effects, within hours (Browne and Lucki, 2013), suggesting a need for reevaluation of the parallel time course idea. Moreover, despite the longstanding belief that classical antidepressants require several weeks to show therapeutic efficacy, a recent meta-analysis suggests that their effects also begin more rapidly than previously thought (Lam, 2012). Very rapid effects of antidepressants seem unlikely to be mediated by increased birth of new neurons, but this is not necessarily a blow to the neurogenesis hypothesis of depression, as the proliferative effects may be important for prolonged or maximal effects of treatment, and the effects of antidepressants on maturation and survival of new neurons, which are only beginning to be examined, could have more rapid functional effects.

\section{Anxiety}

Although the role of adult neurogenesis in anxiety disorders has not been intensively investigated as it has in depressive disorders, the high comorbidity seen between anxiety and depression (Hirschfeld, 2001; Lamers et al, 2011) suggests that any role that neurogenesis in the dentate gyrus might have in depression is likely to affect anxiety disorders as well. Indeed, animal models of depression often produce anxiogenic-like effects as well (David et al, 2009; Fahey et al, 2007; Rainer et al, 2012), and chronic administration of antidepressants and deep brain stimulation tend to decrease anxiety-like behaviors in animal models (David et al, 2009; Dulawa et al, 2004; Schmuckermair et al, 2013).

Classic anxiolytics typically mimic the effects of the inhibitory neurotransmitter GABA (Tallman and Gallager, 1985). These medications produce their anxiolytic effects very rapidly, unlike antidepressants, indicating that their mechanism of action is unlikely to involve slow processes such as the generation or survival of new neurons (see above). Chronic use of anxiolytics, however, could potentially have effects on adult neurogenesis that interact with those of antidepressants when coadministered. Studies have shown mixed results of acute anxiolytic or GABAergic drugs on neurogenesis. The benzodiazepine diazepam had no effect on cell proliferation in the dentate gyrus in male mice or male rats (Sun et al, 2013; Wu and Castrén, 2009), but increased granule cell precursor proliferation in a third study that used female mice and a 10-fold higher dose of the drug (Petrus et al, 2009). There is general agreement that diazepam does not affect survival of the young dentate gyrus neurons in mice or rats (Karten et al, 2006; Sun et al, 2013; Wu and Castrén, 2009). However, activating GABA-A receptors with barbiturates over several days reduced cell proliferation and increased cell survival in mice in one study (Tozuka et al, 2005). This difference between barbiturates and benzodiazepines, both of which act as agonists on the same GABA-A receptor, could potentially be explained by actions of barbiturates at several additional targets (Löscher and Rogawski, 2012). Importantly, 
although diazepam has few, if any, effects on adult neurogenesis on its own, it prevents the proneurogenic effects of fluoxetine on adult neurogenesis and behavior (Sun et al, 2013; Wu and Castrén, 2009), suggesting that although these drugs are frequently used in combination at the start of clinical treatment, this coadministration may be detrimental if neurogenesis plays a role in human depressive illness.

Anxiolytics might be expected to enhance new granule cell maturation, because endogenous GABAergic signaling has been proposed to have this function (Schoenfeld and Gould, 2013). The first synaptic inputs onto new granule neurons are GABAergic, and running, which accelerates granule cell maturation, enhances GABA in the dentate gyrus (Markwardt et al, 2011; Schoenfeld et al, 2013; Snyder et al, 2009b). In fact, the anxiolytic-like effects of running are blocked by GABA receptor antagonists in mice (Schoenfeld et al, 2013), suggesting that running and anxiolytic drugs may share the same mechanism. Little is known about the effects of anxiolytic medications on granule neuron maturation, but pentobarbital increases dendritic length in young granule neurons, whereas the GABA-A receptor antagonist picrotoxin inhibits maturation, decreasing both spine density and dendritic length (Sun et al, 2009). In addition to any effects on maturation, the finding that running increases GABAergic signaling in the dentate gyrus and decreases the activation of new granule neurons by stress (Schoenfeld et al, 2013) suggests that anxiolytic medications may alter the functioning of new neurons in stressful situations. This mechanism would be very different from the increase in the number of new neurons proposed as a mechanism for antidepressants, but it is consistent with very rapid time course of anxiolytic effects.

Several studies have found that synthetic cannabinoids can reduce anxiety (Fabre and McLendon, 1981; Grant et al, 2011; Schindler et al, 2008). Cannabinoid effects on anxietylike behavior in rodents have recently been described (Braida et al, 2007; Jiang et al, 2005; Patel and Hillard, 2006). Cannabinoids and cannabinoid receptor agonists increase the proliferation of new neurons in the adult dentate gyrus (Avraham et al, 2014; Campos et al, 2013; Jiang et al, 2005) and increase new granule cell survival (Wolf et al, 2010). However, the rapid time course of cannabinoid effects on behavior, and dissociations between behavioral and neurogenic effects of different cannabinoids (Wolf et al, 2010), argue against the anxiolytic effects of cannabinoids being mediated by adult neurogenesis.

\section{Schizophrenia}

Animal behavior models and human genetic studies have implicated the hippocampus in the etiology of schizophrenia. One of the best-characterized animal models of schizophrenia is the neonatal ventral hippocampal lesion model that produces periadolescent onset of schizophreniclike behaviors in rats (O'Donnell, 2012; Tseng et al, 2009). Because schizophrenia has a heritable component, researchers have long sought for genetic abnormalities that may lead to a predisposition to developing schizophrenia. Genetic analysis of a Scottish family with a high prevalence of schizophrenia indicated a mutation in the DISC1 (disrupted in schizophrenia 1) gene (Millar et al, 2000) that codes for a scaffolding protein that interacts with different protein partners to promote development and growth (Soares et al, 2011). The locations and time course of DISC1 expression suggest a role in neurogenesis; in the postnatal brain, it is localized primarily to the hippocampus (Austin et al, 2004; Schurov et al, 2004). Downregulation of DISC1 gene in mice has been shown to impair cell proliferation in the adult dentate gyrus (Mao et al, 2009). DISC1 has been suggested to guide migration of new neurons in the dentate gyrus (Namba et al, 2011) and, indeed, knockdown of DISC1 protein in mice leads to accelerated maturation and abnormal morphology of new neurons in the adult dentate gyrus (Duan et al, 2007). These new neurons appear to be misplaced in circuitry and show aberrant physiological characteristics. Another gene, NPAS3, a member of a family of transcription factors known to be involved in a wide array of functions, including neurogenesis (Crews, 1998), has been shown to be affected in schizophrenia (Kamnasaran et al, 2003). Similarly, NPAS3 knockout mice show impaired neurogenesis in adulthood (Pieper et al, 2005).

Research into the effects of antipsychotic medications on adult neurogenesis, however, provide little evidence for a role for adult neurogenesis in treatment for schizophrenia. The classical antipsychotic haloperidol effectively reverses deficits in prepulse inhibition in animal models of schizophrenia (Mansbach et al, 1988). However haloperidol had no effect on neurogenesis in the adult dentate gyrus in several studies, using several doses and treatment regimens and examining long-term survival of new neurons as well as their generation (Halim et al, 2004; Malberg et al, 2000; Wakade et al, 2002; Wang et al, 2004). Similarly, atypical antipsychotics like olanzapine, risperidone, and clozapine were also ineffective at altering adult neurogenesis in several studies (Green et al, 2006; Meyer et al, 2010; Wakade et al, 2002; Wang et al, 2004). One study demonstrated an increase in proliferation with clozapine treatment, but the new cells were lost within 3 weeks, likely before becoming functional, despite ongoing clozapine treatment (Halim et al, 2004). Another found that olanzapine increased cell proliferation (Kodama et al, 2004), in contrast to other studies (Green et al, 2006; Wang et al, 2004); the observed increase was only $20 \%$ over baseline levels, suggesting that there may be a modest and variable effect of this drug on neurogenesis. One group found increased precursor cell proliferation with risperidone and increased survival of new granule cells with both haloperidol and risperidone (Keilhoff et al, 2010a, b). It is unclear why these findings diverge from those of the majority of studies, as the doses, species, and time courses of the studies all overlap. Despite the lack of clear data suggesting effects of antipsychotic medications on adult neurogenesis, it is possible that such effect would emerge when structural changes underlying 
schizophrenia are elucidated and animal models of such changes are generated.

\section{BEHAVIORAL EFFECTS OF INHIBITING ADULT NEUROGENESIS}

\section{Depression}

Short of real-time imaging to track neurogenesis levels in humans, which is not currently possible, the best evidence for a causal role of new neurons in depression will likely come from studies demonstrating depressive-like behavior in animal models of reduced neurogenesis. Rapid or prolonged immobility in the forced swim test (FST), long latency to eat in the novelty-suppressed feeding (NSF) test, and decreased sucrose preference in the sucrose preference test (SPT) are the most commonly used rodent behavioral analogs of depressive behavior. Inhibiting adult neurogenesis, using brain irradiation or the mitotic blocker methylazoxymethanol acetate (MAM), produce no change in immobility in the FST (Airan et al, 2007; Bessa et al, 2009; Holick et al, 2008); however, one study using pharmacogenetic methods to eliminate adult neurogenesis found increased FST immobility (Snyder et al, 2011). One possible explanation for these differential findings is that Snyder et al (2011) measured immobility during the early phase of testing, when animals are least likely to be immobile, whereas other studies followed a common drug testing protocol and measured immobility during the latter part of the test and/or after a pretest. In the NSF test, or related 'cookie test,' several studies found no effect of inhibiting neurogenesis (Meshi et al, 2006; Revest et al, 2009; Santarelli et al, 2003; Surget et al, 2011; Wang et al, 2008; Zhu et al, 2010). Bessa et al (2009) found increased latency to eat under similar conditions; however, the dose of MAM used to inhibit neurogenesis may decrease motivation to eat independent of its effects on neurogenesis (Dupret et al, 2005; Shors et al, 2001). A study using pharmacogenetic methods showed decreased latency to eat, that is, decreased depressive-like behavior, in rats lacking new neurons relative to controls. However, this group found a similar difference in transgenic animals without drug treatment to inhibit neurogenesis, suggesting a transgene insertion effect (Groves et al, 2013). Fewer studies have examined the effects of increasing, as opposed to inhibiting, adult neurogenesis, but mice with increased neurogenesis because of genetic deletion of a cell death gene also show no baseline change in forced swim or NSF behavior (Sahay et al, 2011).

The only study to date to report an effect on NSF found no effect of new neurons under naive conditions but found that acute stress immediately before NSF testing increased latency in animals without neurogenesis but had no effect in controls-suggesting that new neurons can affect depressive-like behavior by buffering the effects of stress (Snyder et al, 2011). This effect on stress response may explain why these mice show depressive-like behavior in the FST under baseline/naive conditions - this test, unlike the NSF test, is very stressful, and hence mice may be responding to the stress of the test itself. These stress response effects are intriguing, given the strong relationship between stress and mental health (described above), and suggest that having low levels of adult neurogenesis might increase susceptibility to the effects of stress on mental health (Figure 2). Interestingly, chronic mild stress does not differentially affect depressive-like behavior in mice with inhibited and intact neurogenesis (David et al, 2009; Surget et al, 2008). This could reflect a role for new neurons only in moderate to severe stress, regardless of duration. Alternatively, as corticosterone treatment and stress inhibit adult neurogenesis, the nonirradiated/nontransgenic control mice in these studies may have decreased numbers of new neurons like the ablated mice, resulting in a lack of behavioral difference.

Although most studies show no change in depressive-like behavior in naive rodents following manipulation of neurogenesis, removal of new neurons alters the behavioral effects of antidepressants. Santarelli et al (2003) were the first to show that eliminating adult neurogenesis via irradiation blocked the antidepressant effect of fluoxetine

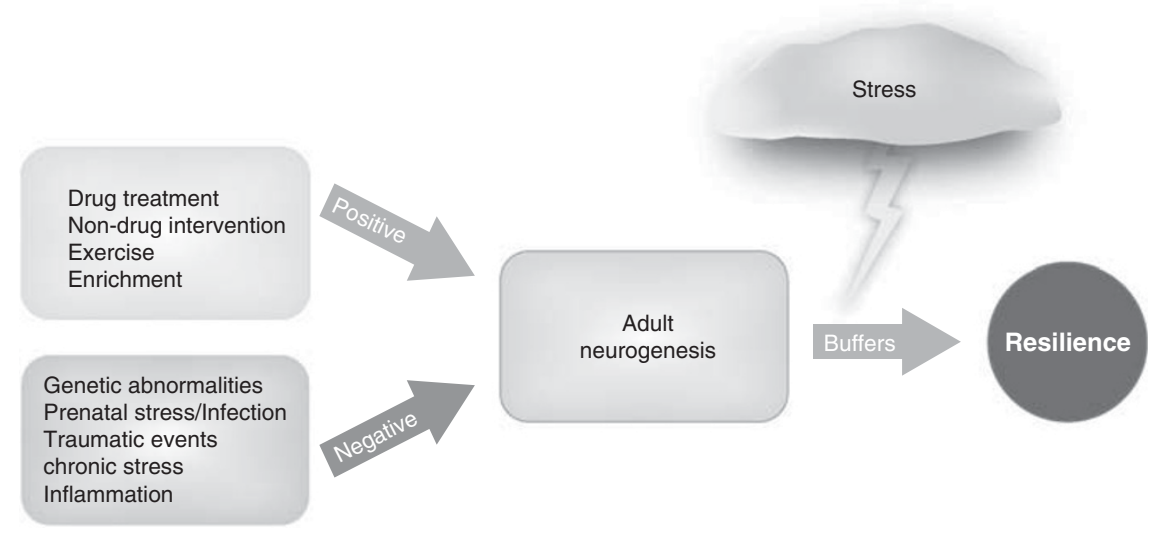

Figure 2. Diagram showing a potential role for new neurons in maintaining mental health. Genetic, developmental, physiological, experiential, and therapeutic interventions can upregulate or downregulate adult neurogenesis. The population of functioning new neurons may protect an individual from negative or inappropriate effects of stress, increasing resilience and thereby promoting mental health. 
on NSF behavior in mice. Since then, several studies have replicated and extended this finding, showing adult neurogenesis is required for the effects of antidepressants on the FST and cookie test as well as on the NSF test (Airan et al, 2007; Surget et al, 2011; Wang et al, 2008). Elimination of adult neurogenesis via irradiation also blocks the beneficial effect of fluoxetine on anhedonia in non-human primates (Perera et al, 2011), indicating that this new neuron requirement holds for primates as well and may be relevant in humans. Inhibiting adult neurogenesis in rodents also prevents the antidepressant effects on LTP and HPA axis reactivity to stress (Surget et al, 2011; Wang et al, 2008). Bessa et al (2009) found that decreasing neurogenesis did not prevent antidepressant effects on anhedonia and learned helplessness in rodents, but the MAM treatment used in this study only partially arrested adult neurogenesis, suggesting that greater inhibition of neurogenesis might be necessary to block the antidepressant effects. The antidepressant effects of fluoxetine in the FST were unaffected by irradiation in a strain of highly anxious mice (Holick et al, 2008), perhaps fitting with the lack of effect of new neurons on anxiety (see below).

\section{Anxiety}

Anxiety-like behavior is generally tested in rodents using exploratory tests like the open field test and elevated plus maze. Lesions of the hippocampus, in particular the ventral hippocampus, decrease anxiety-related behavior, indicating a role for the hippocampus in generating anxiety (Bannerman et al, 2014; Deacon et al, 2002), suggesting that neurogenesis might also play a role in anxiety. However, several studies have failed to find any effect of genetic or irradiation-induced ablation of adult neurogenesis on anxiety-like behavior in the open field test or elevated plus maze, either in naive animals (Jaholkowski et al, 2009; Saxe et al, 2006; Snyder et al, 2011; Wei et al, 2011) or after acute stress (Snyder et al, 2011). A recent meta-analysis of open field and elevated plus maze behavior data from 25 studies also found no significant effects of adult neurogenesis (Groves et al, 2013). Increasing the survival of new neurons also has no effect on anxiety-like behavior in these tasks (Sahay et al, 2011). One study found that deleting the brainderived neurotrophic factor TrkB receptors from new neurons increased anxiety-like behavior on the open field and elevated plus maze (Bergami et al, 2008). It is surprising that deleting a single gene in this neuronal population would have a greater behavioral impact than eliminating the cells altogether. This paradoxical finding suggests that the deletion of this gene may not be limited to new neurons in this model or that changes in TrkB in these neurons has downstream effects in other cell types. In contrast to the lack of effect of adult neurogenesis on anxiety-like behavior, Roughton et al (2012) showed that irradiation during the juvenile period in rodents increased anxiety-like behavior on the open field in adulthood, suggesting that postnatal neurogenesis, and the primary granule cell population that is born during this period, are more important for anxiety than adult-born granule cells.

The NSF test is sensitive to both antidepressants and anxiolytics in rodents, and hence changes in behavior in this test can be interpreted as reflecting anxiety and/or depression (Samuels and Hen, 2011b). Snyder et al (2011) found increased latency to feed after acute stress in mice lacking adult neurogenesis, as described above, potentially suggesting increased anxiety-like behavior. However, because the mice showed no behavioral differences in the elevated plus maze but did behave differently in multiple tests of depressive-like behavior, this NSF test behavior appears more likely to reflect depressive-like than anxietylike behavior.

It is not known whether new neurons are required for the effects of classic anxiolytics. Cannabinoids, however, have anxiolytic-like effects in elevated plus maze and the NSF test that are blocked by ablation of new neurons (Campos et al, 2013; Jiang et al, 2005). Adult neurogenesis is required for the anxiolytic-like effects of cannabinoids in a chronic stress model of anxiety as well as under baseline conditions (Campos et al, 2013). More studies are needed to test the role of new neurons in mediating behavioral effects of cannabinoids and classical anxiolytics.

\section{Schizophrenia}

Schizophrenia-associated symptoms may be the most difficult to model in rodent behavior tests. Diminished prepulse inhibition of startle behavior, which is believed to reflect sensory gating deficits, is often described as a biological marker of schizophrenia, although it is not specific to this condition (Braff et al, 2001). Rats lacking adult neurogenesis, because of irradiation or MAM treatment, show impairments in prepulse inhibition of acoustic startle (Iwata et al, 2008; Maekawa et al, 2009). Irradiated rats also show behavioral abnormalities in social interactions and working memory that are also impaired in human schizophrenia (Iwata et al, 2008). These findings suggest a potential role for new neurons in schizophrenia-related behavior, although a great deal of work is still clearly needed. The effects of antipsychotics in animals following ablation of new neurons has not been tested, but the apparent lack of effects of these medications on the rate of neurogenesis in rodents suggests that the effects on adult neurogenesis are unlikely to underlie their effects. That said, the lack of baseline effects of antipsychotics on neurogenesis does not preclude the effects in models of schizophrenia.

\section{FUTURE RESEARCH DIRECTIONS}

\section{Human Studies}

The most direct evidence for a relationship between adult neurogenesis and mental illness has to come from studies of human patients, even though these studies can at best only 
offer correlational data-and can currently only provide postmortem snapshots. No studies have examined cell proliferation or neurogenesis in patients with anxiety disorders and very few have looked at the rates of neurogenesis in subjects with schizophrenia. One study of postmortem tissue found a decrease in cell proliferation in the dentate gyrus of adults suffering from schizophrenia compared with controls (Reif et al, 2006), although the reported discarding of several samples that had high numbers of Ki67-positive cells suggests potential immunostaining problems in the included samples. It is impossible to make any conclusions about the relationship between adult neurogenesis and schizophrenia or anxiety disorders based on the scant evidence to date.

There have been more studies looking into the role of adult neurogenesis in human depressive disorder. Decreased numbers of MCM-expressing dividing cells were found in postmortem tissue from depressed patients (Boldrini et al, 2009; Lucassen et al, 2010), although no changes have been found in cell expressing two other cell division markers, $\mathrm{PH} 3$ and Ki67, or the stem cell marker nestin (Boldrini et al, 2012; Lucassen et al, 2010; Reif et al, 2006). The current data, therefore, do not strongly support an effect of major depressive disorder on cell proliferation. Examination of antidepressant effects have produced similarly mixed results, showing strong $(6-20 \times)$ increases in nestin-expressing precursor cells in two studies (Boldrini et al, 2009; 2012) but no change in cell division in another (Lucassen et al, 2010). Taken together, these findings suggest a possible association between neurogenesis and depressive disorder, but they also point to several difficulties with postmortem studies. First, immunostaining in human postmortem tissue is difficult, and the resulting staining is generally of much lower quality than immunostaining in perfused rodent brain. Second, the variability in these studies is quite high, and hence even $10 \times$ differences across means can just barely reach statistical significance. Third, without injecting BrdU before death, which is rarely done in human studies (Eriksson et al, 1998), there is no way to follow new cells and compare rates of true mature neuron production.

There is clearly a need for innovative and reliable in vivo methods of identifying new neurons in humans, both in postmortem tissue and, ideally, in the living brain. Live imaging of neuronal precursor cells or recently generated neurons in humans has been discussed, but the available techniques do not yet have the sensitivity and specificity required to detect adult neurogenesis (Couillard-Despres and Aigner, 2011). The advancement of such technology would allow for studies that can address critical questions, such as whether the rate of neurogenesis changes over the course of disease and whether there is a within-subject change in the rate of neurogenesis with treatment. Technology that enables live imaging of adult neurogenesis would be invaluable for resolving basic questions about whether adult neurogenesis plays a role in mental illness.

\section{Animal Models}

Because of the difficulties in studying adult neurogenesis in humans, described above, the vast majority of information on the interplay between adult neurogenesis and mental illness comes from work on rodents. Although work in rodent models has generated many new ideas about potential roles for new neurons in the etiology and treatment of mental disorders, the limitations of studying very complex human thought processes in rodents are clear (Donaldson and Hen, 2014; Hyman, 2014). A handful of studies have investigated the role of new neurons in antidepressant treatment in non-human primates, but these studies are tremendously costly, and it is largely unknown how well non-human primate psychiatric models reflect conditions in humans.

There is a clear need for better rodent models of mental illness. The term 'animal models' of psychiatric disease is used to mean both tests of behaviors that model symptom and manipulations that increase disease-related behaviors in these tests. Both of these need improvement. It is unclear which aspects of mental illness rodents are capable of reproducing. Clearly, 'mice will never have guilty ruminations [or] suicidal thoughts' (Donaldson and Hen, 2014), although they (if rats are included) do show evidence of some mental processes related to psychiatry, such as motivation and empathy (Ben-Ami Bartal et al, 2011; DerAvakian and Markou, 2012; Simpson et al, 2012). But even if rodents could experience many features of human mental illness, it would be difficult to determine with any certainty because of their inability to communicate with us. It is very difficult to imagine, for example, how we would know if a mouse had hallucinations. But the problems with modeling psychiatric illness are not all due to shortcomings of rodents; incomplete understanding of the constellations of symptoms associated with mental illness in humans hinders development of animal models as well. Improved understanding of human symptoms, for example the key features of anhedonia or the relationship between anxiety and depression, will enable generation of better tests of rodent behaviors modeling these symptoms. Although the current rodent models may seem to lead in circles as far as drug development is concerned (Donaldson and Hen, 2014; Hyman, 2014), any improvement on the human or the rodent side could potentially produce a positive feedback loop in which an improved rodent model might generate a new hypothesis about human illness that could then inspire an even better rodent model.

Improvement is also needed in animal models of the other type, that is, manipulations that increase behaviors resembling psychiatric symptoms. There are models of schizophrenic-like behavior in rats, but for the reasons discussed above, it is difficult to determine how well they truly model the disease. Developmental insults and/or chronic stress in adulthood have been used to increase depressive-like behavior in rodents. However, the majority of experiments looking at effects of psychiatric medications 
on neurogenesis or the effects of neurogenesis on mental illness-related behavior have used naive animals, under baseline conditions. Even if animals lacking neurogenesis show no change in psychiatric disease-related behavior under baseline conditions, behavioral changes may result from a combination of altered neurogenesis and a particular adverse experience. In the case of depressive-like behavior, this idea is supported by the finding that mice lacking adult neurogenesis show normal behavior in the NSF test if they are naive but increased depressive behavior following acute stress (Snyder et al, 2011).

Animal models used for work on the role of adult neurogenesis in psychiatric disorders should attempt to model risk factors for developing those diseases rather than focusing on naive animals. Because traumatic life events are so strongly associated with many forms of mental illness, future research should investigate the role of new neurons on the development of behaviors associated with mental illness in various stress models. To date, no studies have looked at the long-lasting effects of acute traumatic events in rodent models of neurogenesis ablation. It is possible that adult-born neurons in the hippocampus may facilitate recovery and general resiliency to salient stressors, whereas animals with impaired or ablated neurogenesis may show heightened and prolonged ill effects of traumatic events (Figure 2). In addition, it is unknown how neurogenesis is functionally involved in behavioral changes produced by stressors occurring prenatally or in early life. Combinations of genetic predispositions, prenatal illness/inflammation, early-life stress, chronic stress in adulthood, and/or single traumatic events may produce behavioral phenotypes that provide insight into the role of neurogenesis in development of and recovery from anxiety, depression, and schizophrenia.

\section{Neurogenesis in Other Regions}

Finally, although the vast majority of research on adult neurogenesis in psychiatric disease has been aimed at the dentate gyrus, new neurons generated in other brain regions could play a role in mental health as well. The brain region that adds the largest number of neurons in adulthood is the olfactory bulb. Although the olfactory bulb may not come to mind as a key region for mental illness, the depressive-like state produced in rodents by removal of the olfactory bulbs and the olfactory changes in depressed human patients suggests a potential association between olfaction and depression (Schablitzky and Pause, 2014; Yuan and Slotnick, 2014). Olfactory deficits are observed in schizophrenia as well (Nguyen et al, 2010; Rupp, 2010). The effects of antipsychotic and anxiolytic medications on cell proliferation in the subventricular zone (SVZ), the source of olfactory bulb neurons, have been examined in a handful of studies, but with mixed results (Green et al, 2006; Kippin et al, 2005; Kodama et al, 2004; Wakade et al, 2002; Yamaguchi and Mori, 2005).
The olfactory epithelium generates new neurons throughout life and therefore offers a source of neural stem cells that is relatively easily accessed in humans. These cells are often studied as potential markers for neurogenic activity in the brain (Féron et al, 1999), although these sensory neurons are not very closely related to the neurons generated in the brain and may not reflect pathological changes in central nervous system stem cells.

Adult neurogenesis has also been reported in other brain areas believed to be involved in depression, anxiety, and schizophrenia, including the amygdala and prefrontal cortex. Adult neurogenesis has been reported in the amygdala of rodents and monkeys (Bernier et al, 2002; Jiang et al, 2014; Takemura, 2005), although the evidence for double labeling of the proliferation marker BrdU and mature neuronal markers is not especially strong. Effects of olfactory bulbectomy, fear conditioning, and fluoxetine have been observed on the numbers of adult-born cells in the amygdala (Jiang et al, 2014; Keilhoff et al, 2006; Okuda et al, 2009), but it is unclear how many of the affected cells are neurons.

Adult neurogenesis has also been reported in the prefrontal cortex of adult rats and primates (Dayer et al, 2005; Gould et al, 1999a, b, 2001). The new neurons are small interneurons and make up only a fraction of the newborn cells in this region (Dayer et al, 2005; Gould et al, 2001). In mice, neocortical adult neurogenesis appears to be almost nonexistent (Snyder et al, 2009a). In rats, the number of new neurons generated in neocortex is quite small relative to the number in the dentate gyrus, but the fraction of neurons produced (of small interneurons or granule cells, respectively) is equivalent in the two regions (Cameron and Dayer, 2008). Nevertheless, the small number of neurons produced across a large volume of cortex in rats makes quantitative studies of new neurons in the adult neocortex very difficult. Several studies have investigated the effects of factors related to mental illness on cell proliferation in the prefrontal cortex. Glucocorticoid treatment and stress inhibit proliferation of NG2-expressing cells, the proposed neuronal precursors, in the prefrontal cortex, and antidepressant treatments, including electroconvulsive shock and fluoxetine, increase proliferation in this region (Alonso, 2000; Banasr et al, 2007; Czéh et al, 2007; Dayer et al, 2005; Madsen et al, 2005). Olanzapine also increases proliferation in the prefrontal cortex (Green et al, 2006; Kodama et al, 2004; Wang et al, 2004). However, as most new daughter cells in the neocortex do not appear to differentiate into neurons (Dayer et al, 2005), it is unclear whether any of these changes reflect effects on neurogenesis. One recent study has reported that chronic fluoxetine treatment increases the generation of GABAergic interneurons in the rodent neocortex (Ohira et al, 2013), although this finding will need to be replicated.

Despite the importance of the amygdala and prefrontal cortex to mental health, the potential contributions of adult neurogenesis in these regions has largely been ignored. This is most likely because of the small numbers of neurons 
generated in these regions, the difficult nature of neurogenesis experiments in these regions, and the poor quality of much of the resulting data. Although the number of neurons produced in these regions is low, production of even small numbers of interneurons is likely to have functional effects (Cameron and Dayer, 2008). Better methods for identifying the particular types of neurons born in the amygdala and neocortex could potentially lead to identification of some of the previously unidentifiable cells generated in these regions as neurons (Dayer et al, 2005). Even without this, better methods for long-term labeling of newborn cells could increase the numbers of new neurons that can be detected, allowing quantitative studies of how these neurons are affected by factors that trigger or treat mental illness. Future studies should also investigate the functional effects of specific ablation of or increases in these new neuron populations. Identifying the location and identity/protein expression pattern of the precursor cells generating new neurons in each brain region will aid in specific targeting of these pools by focal irradiation and pharmacogenetic methods. So little is known about adult neurogenesis in these important regions that this presents a challenge but also a tremendous opportunity for uncovering new links between adult neurogenesis and mental illness.

\section{FUNDING AND DISCLOSURE}

The authors declare no conflict of interest.

\section{ACKNOWLEDGEMENTS}

This work was supported by the Intramural Program of the National Institute of Mental Health, National Institutes of Health, USA, 1ZIAMH002784 (to HAC).

\section{REFERENCES}

Abe H, Hidaka N, Kawagoe C, Odagiri K, Watanabe Y, Ikeda Tet al (2007). Prenatal psychological stress causes higher emotionality, depression-like behavior, and elevated activity in the hypothalamo-pituitary-adrenal axis. Neurosci Res 59: 145-151

Agid O, Shapira B, Zislin J, Ritsner M, Hanin B, Murad H et al (1999). Environment and vulnerability to major psychiatric illness: a case control study of early parental loss in major depression, bipolar disorder and schizophrenia. Mol Psychiatry 4: 163-172.

Aimone JB, Deng W, Gage FH (2014). Adult neurogenesis in the dentate gyrus. In: Derdikman D, Knierim JJ (eds). Space, time and memory in the hippocampal formation. Springer: Vienna, pp 409-429.

Airan RD, Meltzer LA, Roy M, Gong Y, Chen H, Deisseroth K (2007). High-speed imaging reveals neurophysiological links to behavior in an animal model of depression. Science (New York, NY) 317: 819-823.

Aisa B, Elizalde N, Tordera R, Lasheras B, Del Río J, Ramírez MJ (2009). Effects of neonatal stress on markers of synaptic plasticity in the hippocampus: implications for spatial memory. Hippocampus 19: 1222-1231.

Alonso G (2000). Prolonged corticosterone treatment of adult rats inhibits the proliferation of oligodendrocyte progenitors present throughout white and gray matter regions of the brain. Glia 31: 219-231.

Anisman H, Zacharko RM (1982). Depression - the predisposing influence of stress. Behav Brain Sci 5: 89-99.

Antonova E, Sharma T, Morris R, Kumari V (2004). The relationship between brain structure and neurocognition in schizophrenia: a selective review. Schizophr Res 70: $117-145$.
Austin CP, Ky B, Ma L, Morris JA, Shughrue PJ (2004). Expression of Disrupted-InSchizophrenia-1, a schizophrenia-associated gene, is prominent in the mouse hippocampus throughout brain development. Neuroscience 124: 3-10.

Avraham HK, Jiang S, Fu Y, Rockenstein E, Makriyannis A, Zvonok A et al (2014). The cannabinoid $\mathrm{CB}_{2}$ receptor agonist $\mathrm{AM} 1241$ enhances neurogenesis in GFAP/Gp120 transgenic mice displaying deficits in neurogenesis. $\mathrm{Br} J$ Pharmacol 171: 468-479.

Bahi A (2013). Increased anxiety, voluntary alcohol consumption and ethanolinduced place preference in mice following chronic psychosocial stress. Stress (Amsterdam, Netherlands) 16: 441-451.

Bai F, Bergeron M, Nelson DL (2003). Chronic AMPA receptor potentiator (LY451646) treatment increases cell proliferation in adult rat hippocampus. Neuropharmacology 44: 1013-1021.

Baldini S, Restani L, Baroncelli L, Coltelli M, Franco R, Cenni MC et al (2013). Enriched early life experiences reduce adult anxiety-like behavior in rats: a role for insulin-like growth factor 1. J Neurosci 33: 11715-11723.

Banasr M, Soumier A, Hery M, Mocaër E, Daszuta A (2006). Agomelatine, a new antidepressant, induces regional changes in hippocampal neurogenesis. Biol Psychiatry 59: 1087-1096.

Banasr M, Valentine GW, Li X-Y, Gourley SL, Taylor JR, Duman RS (2007). Chronic unpredictable stress decreases cell proliferation in the cerebral cortex of the adult rat. Biol Psychiatry 62: 496-504.

Bannerman DM, Sprengel R, Sanderson DJ, McHugh SB, Rawlins JNP, Monyer H et al (2014). Hippocampal synaptic plasticity, spatial memory and anxiety. Nat Rev Neurosci 15: 1-13.

Beebe LH, Tian L, Morris N, Goodwin A, Allen SS, Kuldau J (2005). Effects of exercise on mental and physical health parameters of persons with schizophrenia. Issues Ment Health Nurs 26: 661-676.

Belarbi K, Arellano C, Ferguson R, Jopson T, Rosi S (2012). Chronic neuroinflammation impacts the recruitment of adult-born neurons into behaviorally relevant hippocampal networks. Brain Behav Immun 26: 18-23.

Ben-Ami Bartal I, Decety J, Mason P (2011). Empathy and pro-social behavior in rats. Science (New York, NY) 334: 1427-1430.

Benaroya-Milshtein N, Hollander N, Apter A, Kukulansky T, Raz N, Wilf A et al (2004). Environmental enrichment in mice decreases anxiety, attenuates stress responses and enhances natural killer cell activity. Eur J Neurosci 20: 1341-1347.

Bengzon J, Kokaia Z, Elmér E, Nanobashvili A, Kokaia M, Lindvall O (1997). Apoptosis and proliferation of dentate gyrus neurons after single and intermittent limbic seizures. Proc Natl Acad Sci USA 94: 10432-10437.

Bergami M, Rimondini R, Santi S, Blum R, Götz M, Canossa M (2008). Deletion of TrkB in adult progenitors alters newborn neuron integration into hippocampal circuits and increases anxiety-like behavior. Proc Natl Acad Sci USA 105: 15570-15575

Bernier PJ, Bédard A, Vinet J, Lévesque M, Parent A (2002). Newly generated neurons in the amygdala and adjoining cortex of adult primates. Proc Natl Acad Sci USA 99: 11464-11469.

Bessa JM, Ferreira D, Melo I, Marques F, Cerqueira JJ, Palha JA et al (2009). The mood-improving actions of antidepressants do not depend on neurogenesis but are associated with neuronal remodeling. Mol Psychiatry 14: 764-773. 739.

Blumenthal JA, Babyak MA, Moore KA, Craighead WE, Herman S, Khatri P et al (1999). Effects of exercise training on older patients with major depression. Arch Intern Med 159: 2349-2356.

Blumenthal JA, Williams RS, Needels TL, Wallace AG (1982). Psychological changes accompany aerobic exercise in healthy middle-aged adults. Psychosom Med 44: 529-536.

Bodnoff SR, Suranyi-Cadotte B, Aitken DH, Quirion R, Meaney MJ (1988). The effects of chronic antidepressant treatment in an animal model of anxiety. Psychopharmacology (Berl) 95: 298-302.

Boehme F, Gil-Mohapel J, Cox A, Patten A, Giles E, Brocardo PS et al (2011). Voluntary exercise induces adult hippocampal neurogenesis and BDNF expression in a rodent model of fetal alcohol spectrum disorders. Eur J Neurosci 33: 1799-1811.

Boldrini M, Hen R, Underwood MD, Rosoklija GB, Dwork AJ, Mann JJ et al (2012). Hippocampal angiogenesis and progenitor cell proliferation are increased with antidepressant use in major depression. Biol Psychiatry 72: 562-571.

Boldrini M, Underwood M, Hen R, Rosoklija G, Dwork A, John Mann J et al (2009). Antidepressants increase neural progenitor cells in the human hippocampus. Neuropsychopharmacology 34: 2376-2389.

Borrell J, Vela JM, Arévalo-Martin A, Molina-Holgado E, Guaza C (2002). Prenatal immune challenge disrupts sensorimotor gating in adult rats. Implications for the etiopathogenesis of schizophrenia. Neuropsychopharmacology 26: 204-215

Braff DL, Geyer MA, Swerdlow NR (2001). Human studies of prepulse inhibition of startle: normal subjects, patient groups, and pharmacological studies. Psychopharmacology (Berl) 156: 234-258. 
Braida D, Limonta V, Malabarba L, Zani A, Sala M (2007). 5-HT1A receptors are involved in the anxiolytic effect of Delta9-tetrahydrocannabinol and AM 404, the anandamide transport inhibitor, in Sprague-Dawley rats. Eur J Pharmacol 555: 156-163.

Brown AS, Hooton J, Schaefer CA, Zhang H, Petkova E, Babulas V et al (2004). Elevated maternal interleukin-8 levels and risk of schizophrenia in adult offspring. Am J Psychiatry 161: 889-895.

Brown AS, van Os J, Driessens C, Hoek HW, Susser ES (2000). Further evidence of relation between prenatal famine and major affective disorder. Am J Psychiatry 157: 190-195.

Browne CA, Lucki I (2013). Antidepressant effects of ketamine: mechanisms underlying fast-acting novel antidepressants. Front Pharmacol 4: 161.

Brzózka MM, Fischer A, Falkai P, Havemann-Reinecke U (2011). Acute treatment with cannabinoid receptor agonist WIN55212.2 improves prepulse inhibition in psychosocially stressed mice. Behav Brain Res 218: 280-287.

Cameron HA, Dayer AG (2008). New interneurons in the adult neocortex: small, sparse, but significant? Biol Psychiatry 63: 650-655

Cameron HA, Woolley CS, Gould E (1993). Adrenal steroid receptor immunoreactivity in cells born in the adult rat dentate gyrus. Brain Res 611: 342-346.

Campbell S, Marriott M, Nahmias C, MacQueen GM (2004). Lower hippocampal volume in patients suffering from depression: a meta-analysis. Am J Psychiatry 161: 598-607.

Campos AC, Ortega Z, Palazuelos J, Fogaça MV, Aguiar DC, Díaz-Alonso J et al (2013). The anxiolytic effect of cannabidiol on chronically stressed mice depends on hippocampal neurogenesis: involvement of the endocannabinoid system. Int J Neuropsychopharmacol 16: 1407-1419.

Chapman DP, Whitfield CL, Felitti VJ, Dube SR, Edwards VJ, Anda RF (2004). Adverse childhood experiences and the risk of depressive disorders in adulthood. J Affect Disord 82: 217-225.

Chen G, Rajkowska G, Du F, Seraji-Bozorgzad N, Manji HK (2000). Enhancement of hippocampal neurogenesis by lithium. J Neurochem 75: 1729-1734.

Chen J, Wang Z, Li M (2011). Multiple 'hits' during postnatal and early adulthood periods disrupt the normal development of sensorimotor gating ability in rats J Psychopharmacol (Oxford) 25: 379-392.

Couillard-Despres S, Aigner L (2011). In vivo imaging of adult neurogenesis. Eur J Neurosci 33: 1037-1044.

Crews ST (1998). Control of cell lineage-specific development and transcription by bHLH-PAS proteins. Genes Dev 12: 607-620.

Czéh B, Müller-Keuker JIH, Rygula R, Abumaria N, Hiemke C, Domenici E et al (2007). Chronic social stress inhibits cell proliferation in the adult medial prefrontal cortex: hemispheric asymmetry and reversal by fluoxetine treatment. Neuropsychopharmacology 32: 1490-1503.

Dagyte G, Van der Zee EA, Postema F, Luiten PGM, Boer Den JA, Trentani A et al (2009). Chronic but not acute foot-shock stress leads to temporary suppression of cell proliferation in rat hippocampus. Neuroscience 162: 904-913.

David DJ, Samuels BA, Rainer Q, Wang J-W, Marsteller D, Mendez I et al (2009). Neurogenesis-dependent and -independent effects of fluoxetine in an animal model of anxiety/depression. Neuron 62: 479-493.

Davidson LM, Baum A (1986). Chronic stress and posttraumatic stress disorders. J Consult Clin Psychol 54: 303-308.

Dayer AG, Cleaver KM, Abouantoun T, Cameron HA (2005). New GABAergic interneurons in the adult neocortex and striatum are generated from different precursors. J Cell Biol 168: 415-427.

Deacon RMJ, Bannerman DM, Rawlins JNP (2002). Anxiolytic effects of cytotoxic hippocampal lesions in rats. Behav Neurosci 116: 494-497.

Dekeyne A, Mannoury la Cour C, Gobert A, Brocco M, Lejeune F, Serres F et al (2008). S32006, a novel 5-HT2C receptor antagonist displaying broad-based antidepressant and anxiolytic properties in rodent models. Psychopharmacology (Berl) 199: 549-568.

Denny CA, Burghardt NS, Schachter DM, Hen R, Drew MR (2012). 4- to 6-weekold adult-born hippocampal neurons influence novelty-evoked exploration and contextual fear conditioning. Hippocampus 22: 1188-1201.

Der-Avakian A, Markou A (2012). The neurobiology of anhedonia and other rewardrelated deficits. Trends Neurosci 35: 68-77.

DiLorenzo TM, Bargman EP, Stucky-Ropp R, Brassington GS, Frensch PA LaFontaine T (1999). Long-term effects of aerobic exercise on psychological outcomes. Prev Med 28: 75-85.

Donaldson ZR, Hen R (2014). From psychiatric disorders to animal models: a bidirectional and dimensional approach. Biol Psychiatry (doi:10.1016/j.biopsych. 2014.02.004; e-pub ahead of print)

Dowlati Y, Herrmann N, Swardfager W, Liu H, Sham L, Reim EK et al (2010). A meta-analysis of cytokines in major depression. Biol Psychiatry 67: 446-457.

Duan X, Chang JH, Ge S, Faulkner RL, Kim JY, Kitabatake Y et al (2007). DisruptedIn-Schizophrenia 1 regulates integration of newly generated neurons in the adult brain. Cell 130: 1146-1158.
Dulawa SC, Holick KA, Gundersen B, Hen R (2004). Effects of chronic fluoxetine in animal models of anxiety and depression. Neuropsychopharmacology 29 1321-1330.

Duman CH, Schlesinger L, Russell DS, Duman RS (2008). Voluntary exercise produces antidepressant and anxiolytic behavioral effects in mice. Brain Res 1199: $148-158$

Duman RS, Heninger GR, Nestler EJ (1997). A molecular and cellular theory of depression. Arch Gen Psychiatry 54: 597-606.

Duman RS, Malberg J, Thome J (1999). Neural plasticity to stress and antidepressant treatment. Biol Psychiatry 46: 1181-1191.

Dupret D, Montaron M-F, Drapeau E, Aurousseau C, Le Moal M, Piazza P-V et al (2005). Methylazoxymethanol acetate does not fully block cell genesis in the young and aged dentate gyrus. Eur J Neurosci 22: 778-783.

Eisch AJ (2002). Adult neurogenesis: implications for psychiatry. Prog Brain Res 138: 315-342.

Ekdahl CT, Claasen J-H, Bonde S, Kokaia Z, Lindvall O (2003). Inflammation is detrimental for neurogenesis in adult brain. Proc Natl Acad Sci USA 100: 13632-13637.

Ellenbroek BA, van den Kroonenberg PT, Cools AR (1998). The effects of an early stressful life event on sensorimotor gating in adult rats. Schizophr Res 30 251-260.

Enayati M, Solati J, Hosseini M-H, Shahi H-R, Saki G, Salari A-A (2012). Maternal infection during late pregnancy increases anxiety- and depression-like behaviors with increasing age in male offspring. Brain Res Bull 87: 295-302.

Eriksson PS, Perfilieva E, Björk-Eriksson T, Alborn AM, Nordborg C, Peterson DA et al (1998). Neurogenesis in the adult human hippocampus. Nat Med 4: 1313-1317.

Espósito MS, Piatti VC, Laplagne DA, Morgenstern NA, Ferrari CC, Pitossi FJ et al (2005). Neuronal differentiation in the adult hippocampus recapitulates embryonic development. J Neurosci 25: 10074-10086.

Fabre LF, McLendon D (1981). The efficacy and safety of nabilone (a synthetic cannabinoid) in the treatment of anxiety. J Clin Pharmacol 21: 377S-382S.

Fahey B, Hickey B, Kelleher D, O'Dwyer A-M, O'Mara SM (2007). The widely-used anti-viral drug interferon-alpha induces depressive- and anxiogenic-like effects in healthy rats. Behav Brain Res 182: 80-87.

Fan X, Pristach C, Liu EY, Freudenreich O, Henderson DC, Goff DC (2007). Elevated serum levels of C-reactive protein are associated with more severe psychopathology in a subgroup of patients with schizophrenia. Psychiatry Res 149: 267-271.

Ferragud A, Haro A, Sylvain A, Velázquez-Sánchez C, Hernández-Rabaza V, Canales JJ (2010). Enhanced habit-based learning and decreased neurogenesis in the adult hippocampus in a murine model of chronic social stress. Behav Brain Res 210: 134-139.

Ferrarelli F, Peterson MJ, Sarasso S, Riedner BA, Murphy MJ, Benca RM et al (2010). Thalamic dysfunction in schizophrenia suggested by whole-night deficits in slow and fast spindles. Am J Psychiatry 167: 1339-1348.

Féron F, Perry C, Hirning MH, McGrath J, Mackay-Sim A (1999). Altered adhesion, proliferation and death in neural cultures from adults with schizophrenia. Schizophr Res 40: 211-218.

Fortier M-E, Luheshi GN, Boksa P (2007). Effects of prenatal infection on prepulse inhibition in the rat depend on the nature of the infectious agent and the stage of pregnancy. Behav Brain Res 181: 270-277.

Fride E, Weinstock M (1988). Prenatal stress increases anxiety related behavior and alters cerebral lateralization of dopamine activity. Life Sci 42: 1059-1065.

Friske JE, Gammie SC (2005). Environmental enrichment alters plus maze, but not maternal defense performance in mice. Physiol Behav 85: 187-194.

Ge S, Yang C-H, Hsu K-S, Ming G-L, Song H (2007). A critical period for enhanced synaptic plasticity in newly generated neurons of the adult brain. Neuron 54: 559-566.

Gerlach JL, McEwen BS (1972). Rat brain binds adrenal steroid hormone: radioautography of hippocampus with corticosterone. Science (New York, NY) 175: $1133-1136$

Geuze E, Vermetten E, Bremner JD (2005). MR-based in vivo hippocampal volumetrics: 2. Findings in neuropsychiatric disorders. Mol Psychiatry 10: 160-184.

Gilabert-Juan J, Belles M, Saez AR, Carceller H, Zamarbide-Fores S, Moltó MD et al (2013). A 'double hit' murine model for schizophrenia shows alterations in the structure and neurochemistry of the medial prefrontal cortex and the hippocampus. Neurobiol Dis 59: 126-140.

Gold PW, Goodwin FK, Chrousos GP (1988). Clinical and biochemical manifestations of depression. Relation to the neurobiology of stress (2). N Engl J Med 319: 413-420

Golub Y, Kaltwasser SF, Mauch CP, Herrmann L, Schmidt U, Holsboer F et al (2011). Reduced hippocampus volume in the mouse model of posttraumatic stress disorder. J Psychiatric Res 45: 650-659. 
Goshen I, Kreisel T, Ben-Menachem-Zidon O, Licht T, Weidenfeld J, Ben-Hur Tet al (2007). Brain interleukin-1 mediates chronic stress-induced depression in mice via adrenocortical activation and hippocampal neurogenesis suppression. $\mathrm{Mol}$ Psychiatry 13: 717-728.

Gould E, Reeves AJ, Fallah M, Tanapat P, Gross CG, Fuchs E (1999a). Hippocampal neurogenesis in adult Old World primates. Proc Natl Acad Sci USA 96: 5263-5267

Gould E, Reeves AJ, Graziano MS, Gross CG (1999b). Neurogenesis in the neocortex of adult primates. Science (New York, NY) 286: 548-552.

Gould E, Vail N, Wagers M, Gross CG (2001). Adult-generated hippocampal and neocortical neurons in macaques have a transient existence. Proc Natl Acad Sci USA 98: 10910-10917.

Grant JE, Odlaug BL, Chamberlain SR, Kim SW (2011). Dronabinol, a cannabinoid agonist, reduces hair pulling in trichotillomania: a pilot study. Psychopharmacology (Berl) 218: 493-502.

Grassi Zucconi G, Cipriani S, Balgkouranidou I, Scattoni R (2006). “One night” sleep deprivation stimulates hippocampal neurogenesis. Brain Res Bull 69: 375-381.

Green W, Patil P, Marsden CA, Bennett GW, Wigmore PM (2006). Treatment with olanzapine increases cell proliferation in the subventricular zone and prefrontal cortex. Brain Res 1070: 242-245.

Groves JO, Leslie I, Huang G-J, Mchugh SB, Taylor A, Mott R et al (2013). Ablating adult neurogenesis in the rat has no effect on spatial processing: evidence from a novel pharmacogenetic model. PLoS Genet 9: e1003718.

Grønli J, Murison R, Bjorvatn B, Sørensen E, Portas CM, Ursin R (2004). Chronic mild stress affects sucrose intake and sleep in rats. Behav Brain Res 150: 139-147.

Gu Y, Arruda-Carvalho M, Wang J, Janoschka SR, Josselyn SA, Frankland PW et al (2012). Optical controlling reveals time-dependent roles for adult-born dentate granule cells. Nat Neurosci 15: 1700-1706.

Halim ND, Weickert CS, McClintock BW, Weinberger DR, Lipska BK (2004). Effects of chronic haloperidol and clozapine treatment on neurogenesis in the adult rat hippocampus. Neuropsychopharmacology 29: 1063-1069.

Hava G, Vered L, Yael M, Mordechai H, Mahoud H (2006). Alterations in behavior in adult offspring mice following maternal inflammation during pregnancy. Dev Psychobiol 48: 162-168.

Hemmingsson E (2014). A new model of the role of psychological and emotional distress in promoting obesity: conceptual review with implications for treatment and prevention. Obes Rev 15: 769-779.

Herring MP, Jacob ML, Suveg C, O'Connor PJ (2011). Effects of short-term exercise training on signs and symptoms of generalized anxiety disorder. Mental Health Physical Activity 4: 71-77.

Hirschfeld RMA (2001). The comorbidity of major depression and anxiety disorders: recognition and management in primary care. Prim Care Companion J Clin Psychiatry 3: 244-254.

Holick KA, Lee DC, Hen R, Dulawa SC (2008). Behavioral effects of chronic fluoxetine in BALB/cJ mice do not require adult hippocampal neurogenesis or the serotonin 1A receptor. Neuropsychopharmacology 33: 406-417.

Holowka DW, King S, Saheb D, Pukall M, Brunet A (2003). Childhood abuse and dissociative symptoms in adult schizophrenia. Schizophr Res 60: 87-90.

Holzer CE, Shea BM, Swanson JW, Leaf PJ, Myers JK, George L et al (1986). The increased risk for specific psychiatric disorders among persons of low socioeconomic status. Am J Social Psychiatry 6: 259-271.

Huot RL, Thrivikraman KV, Meaney MJ, Plotsky PM (2001). Development of adult ethanol preference and anxiety as a consequence of neonatal maternal separation in Long Evans rats and reversal with antidepressant treatment. Psychopharmacology (Berl) 158: 366-373.

Hyman SE (2014). Revitalizing psychiatric therapeutics. Neuropsychopharmacology 39: 220-229.

Ishihama T, Ago Y, Shintani N, Hashimoto H, Baba A, Takuma K et al (2010). Environmental factors during early developmental period influence psychobehavioral abnormalities in adult PACAP-deficient mice. Behav Brain Res 209: 274-280

Ishikawa J, Ogawa Y, Owada Y, Ishikawa A (2014). Hyperlocomotor activity and stress vulnerability during adulthood induced by social isolation after early weaning are prevented by voluntary running exercise before normal weaning period. Behav Brain Res 264: 197-206.

Iwata Y, Suzuki K, Wakuda T, Seki N, Thanseem I, Matsuzaki H et al (2008). Irradiation in adulthood as a new model of schizophrenia. PLoS One 3: e2283.

Jaako-Movits K, Zharkovsky T, Pedersen M, Zharkovsky A (2006). Decreased hippocampal neurogenesis following olfactory bulbectomy is reversed by repeated citalopram administration. Cell Mol Neurobiol 26: 1559-1570.

Jacobs BL, van Praag H, Gage FH (2000). Adult brain neurogenesis and psychiatry: a novel theory of depression. Mol Psychiatry 5: 262-269.

Jacobson-Pick S, Richter-Levin G (2010). Differential impact of juvenile stress and corticosterone in juvenility and in adulthood, in male and female rats. Behav Brain Res 214: 268-276.
Jaholkowski P, Kiryk A, Jedynak P, Ben Abdallah NM, Knapska E, Kowalczyk A et al (2009). New hippocampal neurons are not obligatory for memory formation; cyclin D2 knockout mice with no adult brain neurogenesis show learning. Learn Mem 16: 439-451.

Jakubcakova V, Flachskamm C, Landgraf R, Kimura M (2012). Sleep phenotyping in a mouse model of extreme trait anxiety. PLoS One 7: e40625.

Jankord R, Herman JP (2008). Limbic regulation of hypothalamo-pituitaryadrenocortical function during acute and chronic stress. Ann NY Acad Sci 1148: $64-73$

Jayatissa MN, Bisgaard C, Tingström A, Papp M, Wiborg O (2006). Hippocampal cytogenesis correlates to escitalopram-mediated recovery in a chronic mild stress rat model of depression. Neuropsychopharmacology 31: 2395-2404.

Jha S, Dong B, Sakata K (2011). Enriched environment treatment reverses depression-like behavior and restores reduced hippocampal neurogenesis and protein levels of brain-derived neurotrophic factor in mice lacking its expression through promoter IV. Trans/ Psychiatry 1: e40.

Jiang L, Liu C, Tong J, Mao R, Chen D, Wang $\mathrm{H}$ et al (2014). Fluoxetine pretreatment promotes neuronal survival and maturation after auditory fear conditioning in the rat amygdala. PLoS One 9: e89147.

Jiang W, Zhang Y, Xiao L, Van Cleemput J, Ji S-P, Bai G et al (2005). Cannabinoids promote embryonic and adult hippocampus neurogenesis and produce anxiolytic- and antidepressant-like effects. J Clin Invest 115: 3104-3116.

Kaae SS, Chen F, Wegener G, Madsen TM, Nyengaard JR (2012). Quantitative hippocampal structural changes following electroconvulsive seizure treatment in a rat model of depression. Synapse 66: 667-676.

Kahn-Greene ET, Killgore DB, Kamimori GH, Balkin TJ, Killgore WDS (2007). The effects of sleep deprivation on symptoms of psychopathology in healthy adults. Sleep Med 8: 215-221.

Kalisch R, Schubert M, Jacob W, Kessler MS, Hemauer R, Wigger A et al (2006). Anxiety and hippocampus volume in the rat. Neuropsychopharmacology 31: 925-932.

Kamnasaran D, Muir WJ, Ferguson-Smith MA, Cox DW (2003). Disruption of the neuronal PAS3 gene in a family affected with schizophrenia. J Med Genet 40: 325-332.

Karten YJG, Jones MA, Jeurling SI, Cameron HA (2006). GABAergic signaling in young granule cells in the adult rat and mouse dentate gyrus. Hippocampus 16: 312-320.

Katz RJ (1982). Animal model of depression: pharmacological sensitivity of a hedonic deficit. Pharmacol Biochem Behav 16: 965-968.

Kee N, Teixeira CM, Wang AH, Frankland PW (2007). Preferential incorporation of adult-generated granule cells into spatial memory networks in the dentate gyrus. Nat Neurosci 10: 355-362

Keilhoff G, Becker A, Grecksch G, Bernstein H-G, Wolf G (2006). Cell proliferation is influenced by bulbectomy and normalized by imipramine treatment in a regionspecific manner. Neuropsychopharmacology 31: 1165-1176.

Keilhoff G, Grecksch G, Becker A (2010a). Haloperidol normalized prenatal vitamin $\mathrm{D}$ depletion-induced reduction of hippocampal cell proliferation in adult rats. Neurosci Lett 476: 94-98.

Keilhoff G, Grecksch G, Bernstein H-G, Roskoden T, Becker A (2010b). Risperidone and haloperidol promote survival of stem cells in the rat hippocampus. Eur Arch Psychiatry Clin Neurosci 260: 151-162.

Kempermann G, Kuhn HG, Gage FH (1997). More hippocampal neurons in adult mice living in an enriched environment. Nature 386: 493-495.

Kendler KS, Neale MC, Kessler RC, Heath AC, Eaves LJ (1992). Childhood parental loss and adult psychopathology in women. A twin study perspective. Arch Gen Psychiatry 49: 109-116.

Keshavan MS, Reynolds CF, Miewald MJ, Montrose DM, Sweeney JA, Vasko RC et al (1998). Delta sleep deficits in schizophrenia: evidence from automated analyses of sleep data. Arch Gen Psychiatry 55: 443-448.

Kessler RC, Chiu WT, Demler O, Merikangas KR, Walters EE (2005). Prevalence, severity, and comorbidity of 12-month DSM-IV disorders in the National Comorbidity Survey Replication. Arch Gen Psychiatry 62: 617-627.

Kessler RC, Heeringa S, Lakoma MD, Petukhova M, Rupp AE, Schoenbaum M et al (2008). Individual and societal effects of mental disorders on earnings in the United States: results from the national comorbidity survey replication. Am J Psychiatry 165: 703-711.

Kessler RC, McGonagle KA, Zhao S, Nelson CB, Hughes M, Eshleman S et al (1994). Lifetime and 12-month prevalence of DSM-III-R psychiatric disorders in the United States. Results from the National Comorbidity Survey. Arch Gen Psychiatry 51: 8-19.

Kessler RC, Price RH, Wortman CB (1985). Social factors in psychopathology: stress, social support, and coping processes. Annu Rev Psychology 36: 531-572.

Kippin TE, Kapur S, van Der Kooy D (2005). Dopamine specifically inhibits forebrain neural stem cell proliferation, suggesting a novel effect of antipsychotic drugs. J Neurosci 25: 5815-5823. 
Kodama M, Fujioka T, Duman RS (2004). Chronic olanzapine or fluoxetine administration increases cell proliferation in hippocampus and prefrontal cortex of adult rat. Biol Psychiatry 56: 570-580.

Koenig JI, Elmer Gl, Shepard PD, Lee PR, Mayo C, Joy B et al (2005). Prenatal exposure to a repeated variable stress paradigm elicits behavioral and neuroendocrinological changes in the adult offspring: potential relevance to schizophrenia. Behav Brain Res 156: 251-261.

Koo JW, Park CH, Choi SH, Kim NJ, Kim H-S, Choe JC et al (2003). The postnatal environment can counteract prenatal effects on cognitive ability, cell proliferation, and synaptic protein expression. FASEB J 17: 1556-1558.

Lam RW (2012). Onset, time course and trajectories of improvement with antidepressants. Eur Neuropsychopharmacol 22(Suppl 3): S492-S498.

Lamers F, van Oppen P, Comijs HC, Smit JH, Spinhoven P, van Balkom AJLM et al (2011). Comorbidity patterns of anxiety and depressive disorders in a large cohort study: the Netherlands Study of Depression and Anxiety (NESDA). J Clin Psychiatry 72: 341-348.

Lapmanee S, Charoenphandhu J, Charoenphandhu N (2013). Beneficial effects of fluoxetine, reboxetine, venlafaxine, and voluntary running exercise in stressed male rats with anxiety- and depression-like behaviors. Behav Brain Res 250: 316-325.

Lemaire V, Koehl M, Le Moal M, Abrous DN (2000). Prenatal stress produces learning deficits associated with an inhibition of neurogenesis in the hippocampus. Proc Natl Acad Sci USA 97: 11032-11037.

Lepousez G, Valley MT, Lledo P-M (2013). The impact of adult neurogenesis on olfactory bulb circuits and computations. Annu Rev Physiol 75: 339-363.

Leslie AT, Akers KG, Krakowski AD, Stone SSD, Sakaguchi M, Arruda-Carvalho M et al (2011). Impact of early adverse experience on complexity of adult-generated neurons. Trans/ Psychiatry 1: e35.

Lin Y-L, Wang S (2014). Prenatal lipopolysaccharide exposure increases depression-like behaviors and reduces hippocampal neurogenesis in adult rats. Behav Brain Res 259: 24-34.

Lipska BK, Aultman JM, Verma A, Weinberger DR, Moghaddam B (2002). Neonatal damage of the ventral hippocampus impairs working memory in the rat. Neuropsychopharmacology 27: 47-54.

Löscher W, Rogawski MA (2012). How theories evolved concerning the mechanism of action of barbiturates. Epilepsia 53(Suppl 8): 12-25.

Lucassen P, Meerlo P, Naylor A, van Dam A, Dayer A, Fuchs E et al (2009). Regulation of adult neurogenesis by stress, sleep disruption, exercise and inflammation: Implications for depression and antidepressant action. Eur Neuropsychopharmacol 20: 1-17.

Lucassen PJ, Stumpel MW, Wang Q, Aronica E (2010). Decreased numbers of progenitor cells but no response to antidepressant drugs in the hippocampus of elderly depressed patients. Neuropharmacology 58: 940-949.

Madsen TM, Treschow A, Bengzon J, Bolwig TG, Lindvall O, Tingström A (2000). Increased neurogenesis in a model of electroconvulsive therapy. Biol Psychiatry 47: 1043-1049.

Madsen TM, Yeh DD, Valentine GW, Duman RS (2005). Electroconvulsive seizure treatment increases cell proliferation in rat frontal cortex. Neuropsychopharmacology 30: 27-34.

Maekawa M, Takashima N, Matsumata M, Ikegami S, Kontani M, Hara Y et al (2009). Arachidonic acid drives postnatal neurogenesis and elicits a beneficial effect on prepulse inhibition, a biological trait of psychiatric illnesses. PLoS One 4: e5085.

Malberg JE, Eisch AJ, Nestler EJ, Duman RS (2000). Chronic antidepressant treatment increases neurogenesis in adult rat hippocampus. J Neurosci 20 9104-9110.

Maniam J, Morris MJ (2010). Voluntary exercise and palatable high-fat diet both improve behavioural profile and stress responses in male rats exposed to early life stress: role of hippocampus. Psychoneuroendocrinology 35: 1553-1564.

Mansbach RS, Geyer MA, Braff DL (1988). Dopaminergic stimulation disrupts sensorimotor gating in the rat. Psychopharmacology (Berl) 94: 507-514.

Mao Y, Ge X, Frank CL, Madison JM, Koehler AN, Doud MK et al (2009). Disrupted in schizophrenia 1 regulates neuronal progenitor proliferation via modulation of GSK3beta/beta-catenin signaling. Cell 136: 1017-1031.

Markwardt SJ, Dieni CV, Wadiche JI, Overstreet-Wadiche L (2011). Ivy/neurogliaform interneurons coordinate activity in the neurogenic niche. Nat Neurosci 14 1407-1409.

Martisova E, Solas M, Horrillo I, Ortega JE, Meana JJ, Tordera RM et al (2012). Long lasting effects of early-life stress on glutamatergic/GABAergic circuitry in the rat hippocampus. Neuropharmacology 62: 1944-1953.

Matos RJB, Orozco-Solís R, Lopes de Souza S, Manhães-de-Castro R, BolañosJiménez $F$ (2011). Nutrient restriction during early life reduces cell proliferation in the hippocampus at adulthood but does not impair the neuronal differentiation process of the new generated cells. Neuroscience 196: 16-24.
McCauley J, Kern DE, Kolodner K, Dill L, Schroeder AF, DeChant HK et al (1997). Clinical characteristics of women with a history of childhood abuse: unhealed wounds. JAMA 277: 1362-1368.

McEwen BS (2004). Protection and damage from acute and chronic stress: allostasis and allostatic overload and relevance to the pathophysiology of psychiatric disorders. Ann NY Acad Sci 1032: 1-7.

McEwen BS, Weiss JM, Schwartz LS (1968). Selective retention of corticosterone by limbic structures in rat brain. Nature 220: 911-912.

McOmish CE, Burrows E, Howard M, Scarr E, Kim D, Shin H-S et al (2008). Phospholipase C-beta1 knockout mice exhibit endophenotypes modeling schizophrenia which are rescued by environmental enrichment and clozapine administration. Mol Psychiatry 13: 661-672.

Meshi D, Drew MR, Saxe M, Ansorge MS, David D, Santarelli L et al (2006). Hippocampal neurogenesis is not required for behavioral effects of environmental enrichment. Nat Neurosci 9: 729-731.

Meyer U, Knuesel I, Nyffeler M, Feldon J (2010). Chronic clozapine treatment mproves prenatal infection-induced working memory deficits without influencing adult hippocampal neurogenesis. Psychopharmacology (Berl) 208: 531-543.

Milgram NW, Siwak-Tapp CT, Araujo J, Head E (2006). Neuroprotective effects of cognitive enrichment. Ageing Res Rev 5: 354-369.

Millar JK, Wilson-Annan JC, Anderson S, Christie S, Taylor MS, Semple CA et al (2000). Disruption of two novel genes by a translocation co-segregating with schizophrenia. Hum Mol Genet 9: 1415-1423.

Mirescu C, Peters JD, Gould E (2004). Early life experience alters response of adult neurogenesis to stress. Nat Neurosci 7: 841-846.

Mirescu C, Peters JD, Noiman L, Gould E (2006). Sleep deprivation inhibits adult neurogenesis in the hippocampus by elevating glucocorticoids. Proc Natl Acad Sci USA 103: 19170-19175.

Moffitt TE, Caspi A, Harrington H, Milne BJ, Melchior M, Goldberg D et al (2007). Generalized anxiety disorder and depression: childhood risk factors in a birth cohort followed to age 32. Psychol Med 37: 441-452.

Monje ML, Toda H, Palmer TD (2003). Inflammatory blockade restores adult hippocampal neurogenesis. Science (New York, NY) 302: 1760-1765.

Namba T, Ming G-L, Song H, Waga C, Enomoto A, Kaibuchi K et al (2011). NMDA receptor regulates migration of newly generated neurons in the adult hippocampus via Disrupted-In-Schizophrenia 1 (DISC1). J Neurochem 118: 34-44.

Nelson MD, Saykin AJ, Flashman LA, Riordan HJ (1998). Hippocampal volume reduction in schizophrenia as assessed by magnetic resonance imaging: a metaanalytic study. Arch Gen Psychiatry 55: 433-440.

Nguyen AD, Shenton ME, Levitt JJ (2010). Olfactory dysfunction in schizophrenia: a review of neuroanatomy and psychophysiological measurements. Harv Rev Psychiatry 18: 279-292.

O'Donnell P (2012). Cortical disinhibition in the neonatal ventral hippocampal lesion model of schizophrenia: new vistas on possible therapeutic approaches. Pharmacol Ther 133: 19-25.

Ohira K, Takeuchi R, Shoji H, Miyakawa T (2013). Fluoxetine-induced cortical adult neurogenesis. Neuropsychopharmacology 38: 909-920.

Okuda H, Tatsumi K, Makinodan M, Yamauchi T, Kishimoto T, Wanaka A (2009). Environmental enrichment stimulates progenitor cell proliferation in the amygdala. J Neurosci Res 87: 3546-3553.

Oliver PL, Sobczyk MV, Maywood ES, Edwards B, Lee S, Livieratos A et al (2012). Disrupted circadian rhythms in a mouse model of schizophrenia. Curr Biol 22: 314-319.

Palmer AA, Printz DJ, Butler PD, Dulawa SC, Printz MP (2004). Prenatal protein deprivation in rats induces changes in prepulse inhibition and NMDA receptor binding. Brain Res 996: 193-201.

Parent JM, Yu TW, Leibowitz RT, Geschwind DH, Sloviter RS, Lowenstein DH (1997). Dentate granule cell neurogenesis is increased by seizures and contributes to aberrant network reorganization in the adult rat hippocampus. J Neurosci 17: 3727-3738.

Patel S, Hillard CJ (2006). Pharmacological evaluation of cannabinoid receptor ligands in a mouse model of anxiety: further evidence for an anxiolytic role for endogenous cannabinoid signaling. J Pharmacol Exp Ther 318: 304-311.

Perera TD, Coplan JD, Lisanby SH, Lipira CM, Arif M, Carpio C et al (2007). Antidepressant-induced neurogenesis in the hippocampus of adult nonhuman primates. J Neurosci 27: 4894-4901.

Perera TD, Dwork AJ, Keegan KA, Thirumangalakudi L, Lipira CM, Joyce N et al (2011). Necessity of hippocampal neurogenesis for the therapeutic action of antidepressants in adult nonhuman primates. PLoS One 6: e17600.

Pervanidou P, Kolaitis G, Charitaki S, Margeli A, Ferentinos S, Bakoula C et al (2007). Elevated morning serum interleukin (IL)-6 or evening salivary cortisol concentrations predict posttraumatic stress disorder in children and adolescents six months after a motor vehicle accident. Psychoneuroendocrinology 32: 991-999.

Petrus DS, Fabel K, Kronenberg G, Winter C, Steiner B, Kempermann G (2009). NMDA and benzodiazepine receptors have synergistic and antagonistic effects on precursor cells in adult hippocampal neurogenesis. Eur J Neurosci 29: 244-252. 
Pêgo JM, Sousa JC, Almeida OFX, Sousa N (2010). Stress and the neuroendocrinology of anxiety disorders. Curr Top Behav Neurosci 2: 97-117.

Pham K, Nacher J, Hof PR, McEwen BS (2003). Repeated restraint stress suppresses neurogenesis and induces biphasic PSA-NCAM expression in the adult rat dentate gyrus. Eur J Neurosci 17: 879-886.

Phillips KG, Bartsch U, McCarthy AP, Edgar DM, Tricklebank MD, Wafford KA et al (2012). Decoupling of sleep-dependent cortical and hippocampal interactions in a neurodevelopmental model of schizophrenia. Neuron 76: 526-533.

Piatti VC, Davies-Sala MG, Espósito MS, Mongiat LA, Trinchero MF, Schinder AF (2011). The timing for neuronal maturation in the adult hippocampus is modulated by local network activity. J Neurosci 31: 7715-7728.

Pickett KE, Wilkinson RG (2010). Inequality: an underacknowledged source of mental illness and distress. Br J Psychiatry 197: 426-428.

Pieper AA, Wu X, Han TW, Estill SJ, Dang Q, Wu LC et al (2005). The neuronal PAS domain protein 3 transcription factor controls FGF-mediated adult hippocampal neurogenesis in mice. Proc Natl Acad Sci USA 102: 14052-14057.

Pohl J, Olmstead MC, Wynne-Edwards KE, Harkness K, Menard JL (2007). Repeated exposure to stress across the childhood-adolescent period alters rats' anxiety- and depression-like behaviors in adulthood: the importance of stressor type and gender. Behav Neurosci 121: 462-474.

Pollin W (1972). The pathogenesis of schizophrenia. Possible relationships between genetic, biochemical, and experiential factors. Arch Gen Psychiatry 27: 29-37.

Popa D, Yacoubi El M, Vaugeois J-M, Hamon M, Adrien J (2006). Homeostatic regulation of sleep in a genetic model of depression in the mouse: effects of muscarinic and 5-HT1A receptor activation. Neuropsychopharmacology 31: 1637-1646.

Porsolt RD, Anton G, Blavet N, Jalfre M (1978). Behavioural despair in rats: a new model sensitive to antidepressant treatments. Eur J Pharmacol 47: 379-391.

Rainer Q, Xia L, Guilloux J-P, Gabriel C, Mocaër E, Hen R et al (2012). Beneficial behavioural and neurogenic effects of agomelatine in a model of depression/ anxiety. Int J Neuropsychopharmacol 15: 321-335.

Raison CL, Rutherford RE, Woolwine BJ, Shuo C, Schettler P, Drake DF et al (2012). A randomized controlled trial of the tumor necrosis factor antagonist infliximab for treatment-resistant depression: the role of baseline inflammatory biomarkers. Arch Gen Psychiatry 70: 31-41.

Reichenberg A, Yirmiya R, Schuld A, Kraus T, Haack M, Morag A et al (2001). Cytokine-associated emotional and cognitive disturbances in humans. Arch Gen Psychiatry 58: 445-452.

Reif A, Fritzen S, Finger M, Strobel A, Lauer M, Schmitt A et al (2006). Neural stem cell proliferation is decreased in schizophrenia, but not in depression. Mol Psychiatry 11: 514-522.

Revest J-M, Dupret D, Koehl M, Funk-Reiter C, Grosjean N, Piazza P-V et al (2009). Adult hippocampal neurogenesis is involved in anxiety-related behaviors. Mol Psychiatry 14: 959-967.

Rohleder N, Joksimovic L, Wolf JM, Kirschbaum C (2004). Hypocortisolism and increased glucocorticoid sensitivity of pro-Inflammatory cytokine production in Bosnian war refugees with posttraumatic stress disorder. Biol Psychiatry 55: 745-751.

Romeo RD, Mueller A, Sisti HM, Ogawa S, McEwen BS, Brake WG (2003). Anxiety and fear behaviors in adult male and female C57BL/6 mice are modulated by maternal separation. Horm Behav 43: 561-567.

Roozendaal B, Phillips RG, Power AE, Brooke SM, Sapolsky RM, McGaugh JL (2001). Memory retrieval impairment induced by hippocampal CA3 lesions is blocked by adrenocortical suppression. Nat Neurosci 4: 1169-1171.

Roughton K, Kalm M, Blomgren K (2012). Sex-dependent differences in behavior and hippocampal neurogenesis after irradiation to the young mouse brain. Eur $J$ Neurosci 36: 2763-2772.

Rupp Cl (2010). Olfactory function and schizophrenia: an update. Curr Opin Psychiatry 23: 97-102.

Sachs BD, Rodriguiz RM, Siesser WB, Kenan A, Royer EL, Jacobsen JPR et al (2013). The effects of brain serotonin deficiency on behavioural disinhibition and anxiety-like behaviour following mild early life stress. Int J Neuropsychopharmacol 16: 2081-2094

Sahay A, Hen R (2007). Adult hippocampal neurogenesis in depression. Nat Neurosci 10: 1110-1115.

Sahay A, Scobie KN, Hill AS, O'Carroll CM, Kheirbek MA, Burghardt NS et al (2011). Increasing adult hippocampal neurogenesis is sufficient to improve pattern separation. Nature 472: 466-470.

Samuels BA, Hen R (2011a). Neurogenesis and affective disorders. Eur J Neurosci 33: 1152-1159.

Samuels BA, Hen R (2011b). Novelty-suppressed feeding in the mouse. In: Gould TD (ed). Mood and Anxiety Related Phenotypes in Mice Characterization Using Behavioral Tests, Volume II. Humana Press: New York, 63: 107-121.

Santarelli L, Saxe M, Gross C, Surget A, Battaglia F, Dulawa S et al (2003). Requirement of hippocampal neurogenesis for the behavioral effects of antidepressants. Science (New York, NY) 301: 805-809.
Sapolsky RM (2000). Glucocorticoids and hippocampal atrophy in neuropsychiatric disorders. Arch Gen Psychiatry 57: 925-935.

Sar V, Taycan O, Bolat N, Ozmen M, Duran A, Oztürk E et al (2010). Childhood trauma and dissociation in schizophrenia. Psychopathology 43: 33-40.

Saxe MD, Battaglia F, Wang J-W, Malleret G, David DJ, Monckton JE et al (2006). Ablation of hippocampal neurogenesis impairs contextual fear conditioning and synaptic plasticity in the dentate gyrus. Proc Natl Acad Sci USA 103: 17501-17506.

Schablitzky S, Pause BM (2014). Sadness might isolate you in a non-smelling world: olfactory perception and depression. Front Psychol 5: 45.

Schaefers ATU (2013). Rearing conditions and domestication background determine regulation of hippocampal cell proliferation and survival in adulthood-laboratory CD1 and C57BI/6 mice versus wild house mice. Neuroscience 228: 120-127.

Schäfer I, Fisher HL, Aderhold V, Huber B, Hoffmann-Langer L, Golks D et al (2012). Dissociative symptoms in patients with schizophrenia: relationships with childhood trauma and psychotic symptoms. Compr Psychiatry 53: 364-371.

Schindler F, Anghelescu I, Regen F, Jockers-Scherubl M (2008). Improvement in refractory obsessive compulsive disorder with dronabinol. Am J Psychiatry 165: 536-537.

Schmidt-Hieber C, Jonas P, Bischofberger J (2004). Enhanced synaptic plasticity in newly generated granule cells of the adult hippocampus. Nature 429: 184-187.

Schmuckermair C, Gaburro S, Sah A, Landgraf R, Sartori SB, Singewald N (2013). Behavioral and neurobiological effects of deep brain stimulation in a mouse model of high anxiety- and depression-like behavior. Neuropsychopharmacology 38: 1234-1244.

Schoenfeld TJ, Gould E (2012). New neurons retire early. Nat Neurosci 15: 1611-1612.

Schoenfeld TJ, Gould E (2013). Differential effects of stress and glucocorticoids on adult neurogenesis. Curr Top Behav Neurosci 15: 139-164.

Schoenfeld TJ, Rada P, Pieruzzini PR, Hsueh B, Gould E (2013). Physical exercise prevents stress-induced activation of granule neurons and enhances local inhibitory mechanisms in the dentate gyrus. J Neurosci 33: 7770-7777.

Schurov IL, Handford EJ, Brandon NJ, Whiting PJ (2004). Expression of disrupted in schizophrenia 1 (DISC1) protein in the adult and developing mouse brain indicates its role in neurodevelopment. Mol Psychiatry 9: 1100-1110.

Scott BW, Wojtowicz JM, Burnham WM (2000). Neurogenesis in the dentate gyrus of the rat following electroconvulsive shock seizures. Exp Neurol 165: 231-236.

Sheline YI, Gado MH, Kraemer HC (2003). Untreated depression and hippocampal volume loss. Am J Psychiatry 160: 1516-1518.

Shors TJ, Miesegaes G, Beylin A, Zhao M, Rydel T, Gould E (2001). Neurogenesis in the adult is involved in the formation of trace memories. Nature 410: 372-376.

Silva RH, Kameda SR, Carvalho RC, Takatsu-Coleman AL, Niigaki ST, Abílio VC et al (2004). Anxiogenic effect of sleep deprivation in the elevated plus-maze test in mice. Psychopharmacology (Berl) 176: 115-122.

Simpson EH, Waltz JA, Kellendonk C, Balsam PD (2012). Schizophrenia in translation: dissecting motivation in schizophrenia and rodents. Schizophr Bull 38: 1111-1117.

Snyder JS, Choe JS, Clifford MA, Jeurling SI, Hurley P, Brown A et al (2009a). Adultborn hippocampal neurons are more numerous, faster maturing, and more involved in behavior in rats than in mice. J Neurosci 29: 14484-14495.

Snyder JS, Clifford MA, Jeurling SI, Cameron HA (2012). Complementary activation of hippocampal-cortical subregions and immature neurons following chronic training in single and multiple context versions of the water maze. Behav Brain Res 227: 330-339.

Snyder JS, Glover LR, Sanzone KM, Kamhi JF, Cameron HA (2009b). The effects of exercise and stress on the survival and maturation of adult-generated granule cells. Hippocampus 19: 898-906.

Snyder JS, Hong NS, McDonald RJ, Wojtowicz JM (2005). A role for adult neurogenesis in spatial long-term memory. Neuroscience 130: 843-852.

Snyder JS, Radik R, Wojtowicz JM, Cameron HA (2009c). Anatomical gradients of adult neurogenesis and activity: young neurons in the ventral dentate gyrus are activated by water maze training. Hippocampus 19: 360-370.

Snyder JS, Soumier A, Brewer M, Pickel J, Cameron HA (2011). Adult hippocampal neurogenesis buffers stress responses and depressive behaviour. Nature 476: 458-461.

Soares DC, Carlyle BC, Bradshaw NJ, Porteous DJ (2011). DISC1: structure, function, and therapeutic potential for major mental illness. ACS Chem Neurosci 2: 609-632.

Soumier A, Banasr M, Lortet S, Masmejean F, Bernard N, Kerkerian-Le-Goff L et al (2009). Mechanisms contributing to the phase-dependent regulation of neurogenesis by the novel antidepressant, agomelatine, in the adult rat hippocampus. Neuropsychopharmacology 34: 2390-2403.

Southwick SM, Vythilingam M, Charney DS (2005). The psychobiology of depression and resilience to stress: implications for prevention and treatment. Annu Rev Clin Psychol 1: 255-291. 
St Clair D, Xu M, Wang P, Yu Y, Fang Y, Zhang F et al (2005). Rates of adult schizophrenia following prenatal exposure to the Chinese famine of 1959-1961. JAMA 294: 557-562.

Stein AD, Pierik FH, Verrips GHW, Susser ES, Lumey LH (2009). Maternal exposure to the Dutch famine before conception and during pregnancy: quality of life and depressive symptoms in adult offspring. Epidemiology 20: 909-915.

Stojanovic A, Martorell L, Montalvo I, Ortega L, Monseny R, Vilella E et al (2014). Increased serum interleukin-6 levels in early stages of psychosis: associations with at-risk mental states and the severity of psychotic symptoms. Psychoneuroendocrinology 41: 23-32.

Stranahan AM, Khalil D, Gould E (2006). Social isolation delays the positive effects of running on adult neurogenesis. Nat Neurosci 9: 526-533.

Sun B, Halabisky B, Zhou Y, Palop JJ, Yu G, Mucke L et al (2009). Imbalance between GABAergic and glutamatergic transmission impairs adult neurogenesis in an animal model of Alzheimer's disease. Cell Stem Cell 5: 624-633.

Sun Y, Evans J, Russell B, Kydd R, Connor B (2013). A benzodiazepine impairs the neurogenic and behavioural effects of fluoxetine in a rodent model of chronic stress. Neuropharmacology 72: 20-28.

Surget A, Saxe M, Leman S, Ibarguen-Vargas Y, Chalon S, Griebel G et al (2008). Drug-dependent requirement of hippocampal neurogenesis in a model of depression and of antidepressant reversal. Biol Psychiatry 64: 293-301.

Surget A, Tanti A, Leonardo ED, Laugeray A, Rainer Q, Touma C et al (2011). Antidepressants recruit new neurons to improve stress response regulation. $\mathrm{Mol}$ Psychiatry 16: 1177-1188.

Swerdlow NR, Halim N, Hanlon FM, Platten A, Auerbach PP (2001). Lesion size and amphetamine hyperlocomotion after neonatal ventral hippocampal lesions: more is less. Brain Res Bull 55: 71-77.

Takao K, Kobayashi K, Hagihara H, Ohira K, Shoji H, Hattori S et al (2013). Deficiency of schnurri-2, an MHC enhancer binding protein, induces mild chronic inflammation in the brain and confers molecular, neuronal, and behaviora phenotypes related to schizophrenia. Neuropsychopharmacology 38: 1409-1425.

Takemura NU (2005). Evidence for neurogenesis within the white matter beneath the temporal neocortex of the adult rat brain. Neuroscience 134: 121-132.

Taliaz D, Loya A, Gersner R, Haramati S, Chen A, Zangen A (2011). Resilience to chronic stress is mediated by hippocampal brain-derived neurotrophic factor J Neurosci 31: 4475-4483.

Tallman JF, Gallager DW (1985). The GABA-ergic system: a locus of benzodiazepine action. Annu Rev Neurosci 8: 21-44.

Tamura M, Sajo M, Kakita A, Matsuki N, Koyama R (2011). Prenatal stress inhibits neuronal maturation through downregulation of mineralocorticoid receptors. J Neurosci 31: 11505-11514.

Tashiro A, Makino H, Gage FH (2007). Experience-specific functional modification of the dentate gyrus through adult neurogenesis: a critical period during an immature stage. J Neurosci 27: 3252-3259.

Taylor DJ, Lichstein KL, Durrence HH, Reidel BW, Bush AJ (2005). Epidemiology of insomnia, depression, and anxiety. Sleep 28: 1457-1464.

Tkachenko O, Olson EA, Weber M, Preer LA, Gogel H, Killgore WDS (2014). Sleep difficulties are associated with increased symptoms of psychopathology. Exp Brain Res 232: 1567-1574.

Tozuka Y, Fukuda S, Namba T, Seki T, Hisatsune T (2005). GABAergic excitation promotes neuronal differentiation in adult hippocampal progenitor cells. Neuron 47: 803-815

Tseng KY, Chambers RA, Lipska BK (2009). The neonatal ventral hippocampal lesion as a heuristic neurodevelopmental model of schizophrenia. Behav Brain Res 204: 295-305.

Urakawa S, Takamoto K, Hori E, Sakai N, Ono T, Nishijo H (2013). Rearing in enriched environment increases parvalbumin-positive small neurons in the amygdala and decreases anxiety-like behavior of male rats. BMC Neurosci 14: 13.

Vallières L, Campbell IL, Gage FH, Sawchenko PE (2002). Reduced hippocampal neurogenesis in adult transgenic mice with chronic astrocytic production of interleukin-6. J Neurosci 22: 486-492.

van Praag H, Kempermann G, Gage FH (1999). Running increases cell proliferation and neurogenesis in the adult mouse dentate gyrus. Nat Neurosci 2: 266-270.

van Praag H, Schinder AF, Christie BR, Toni N, Palmer TD, Gage FH (2002). Functional neurogenesis in the adult hippocampus. Nature 415: 1030-1034.

Veena J, Srikumar BN, Mahati K, Bhagya V, Raju TR, Shankaranarayana Rao BS (2009a). Enriched environment restores hippocampal cell proliferation and ameliorates cognitive deficits in chronically stressed rats. J Neurosci Res 87: 831-843.

Veena J, Srikumar BN, Raju TR, Shankaranarayana Rao BS (2009b). Exposure to enriched environment restores the survival and differentiation of new born cells in the hippocampus and ameliorates depressive symptoms in chronically stressed rats. Neurosci Lett 455: 178-182.
Vythilingam M, Heim C, Newport J, Miller AH, Anderson E, Bronen R et al (2002). Childhood trauma associated with smaller hippocampal volume in women with major depression. Am J Psychiatry 159: 2072-2080.

Wakade CG, Mahadik SP, Waller JL, Chiu F-C (2002). Atypical neuroleptics stimulate neurogenesis in adult rat brain. J Neurosci Res 69: 72-79.

Walf AA, Frye CA (2007). Estradiol decreases anxiety behavior and enhances inhibitory avoidance and gestational stress produces opposite effects. Stress (Amsterdam, Netherlands) 10: 251-260.

Wang H-D, Dunnavant FD, Jarman T, Deutch AY (2004). Effects of antipsychotic drugs on neurogenesis in the forebrain of the adult rat. Neuropsychopharmacology 29: 1230-1238.

Wang J-W, David DJ, Monckton JE, Battaglia F, Hen R (2008). Chronic fluoxetine stimulates maturation and synaptic plasticity of adult-born hippocampal granule cells. J Neurosci 28: 1374-1384.

Watson JB, Mednick SA, Huttunen M, Wang X (1999). Prenatal teratogens and the development of adult mental illness. Dev Psychopathol 11: 457-466.

Wei L, Meaney MJ, Duman RS, Kaffman A (2011). Affiliative behavior requires juvenile, but not adult neurogenesis. J Neurosci 31: 14335-14345.

Whitfield CL, Dube SR, Felitti VJ, Anda RF (2005). Adverse childhood experiences and hallucinations. Child Abuse Negl 29: 797-810.

Wichers MC, Kenis G, Koek GH, Robaeys G, Nicolson NA, Maes M (2007). Interferon-alpha-induced depressive symptoms are related to changes in the cytokine network but not to cortisol. J Psychoso Res 62: 207-214.

Wilkin MM, Waters P, McCormick CM, Menard JL (2012). Intermittent physical stress during early- and mid-adolescence differentially alters rats' anxiety- and depression-like behaviors in adulthood. Behav Neurosci 126: 344-360.

Willner P, Towell A, Sampson D, Sophokleous S, Muscat R (1987). Reduction of sucrose preference by chronic unpredictable mild stress, and its restoration by a tricyclic antidepressant. Psychopharmacology (Berl) 93: 358-364.

Wohleb ES, Hanke ML, Corona AW, Powell ND, Stiner LM, Bailey MT et al (2011). $\beta$ Adrenergic receptor antagonism prevents anxiety-like behavior and microglial reactivity induced by repeated social defeat. J Neurosci 31: 6277-6288.

Wolf SA, Bick-Sander A, Fabel K, Leal-Galicia P, Tauber S, Ramírez-Rodríguez G et al (2010). Cannabinoid receptor CB1 mediates baseline and activity-induced survival of new neurons in adult hippocampal neurogenesis. Cell Commun Signal 8: 12

Wolf SA, Melnik A, Kempermann G (2011). Physical exercise increases adult neurogenesis and telomerase activity, and improves behavioral deficits in a mouse model of schizophrenia. Brain Behav Immun 25: 971-980.

Workman JL, Fonken LK, Gusfa J, Kassouf KM, Nelson RJ (2011). Post-weaning environmental enrichment alters affective responses and interacts with behavioral testing to alter nNOS immunoreactivity. Pharmacol Biochem Behav 100: 25-32.

Wu X Castrén E (2009). Co-treatment with diazepam prevents the effects of fluoxetine on the proliferation and survival of hippocampal dentate granule cells. Biol Psychiatry 66: 5-8.

Yamaguchi M, Mori K (2005). Critical period for sensory experience-dependent survival of newly generated granule cells in the adult mouse olfactory bulb. Proc Natl Acad Sci USA 102: 9697-9702.

Yildirim E, Erol K, Ulupinar E (2012). Effects of sertraline on behavioral alterations caused by environmental enrichment and social isolation. Pharmacol Biochem Behav 101: 278-287

Yuan T-F, Slotnick BM (2014). Roles of olfactory system dysfunction in depression. Prog Neuropsychopharmacol Biol Psychiatry 54C: 26-30.

Zhang Y, Mao R-R, Chen Z-F, Tian M, Tong D-L, Gao Z-R et al (2014). Deep-brain magnetic stimulation promotes adult hippocampal neurogenesis and alleviates stress-related behaviors in mouse models for neuropsychiatric disorders. Mol Brain 7: 11.

Zhao C, Teng EM, Summers RG, Ming G-L, Gage FH (2006). Distinct morphological stages of dentate granule neuron maturation in the adult mouse hippocampus. J Neurosci 26: 3-11.

Zhao C, Warner-Schmidt J, Duman RS, Gage FH (2012). Electroconvulsive seizure promotes spine maturation in newborn dentate granule cells in adult rat. Dev Neurobiol 72: 937-942.

Zhu X-H, Yan H-C, Zhang J, Qu H-D, Qu X-S, Chen L et al (2010). Intermittent hypoxia promotes hippocampal neurogenesis and produces antidepressant-like effects in adult rats. J Neurosci 30: 12653-12663.

Zimmerman FJ, Katon W (2005). Socioeconomic status, depression disparities, and financial strain: what lies behind the income-depression relationship? Health Econ 14: 1197-1215

Zuena AR, Mairesse J, Casolini P, Cinque C, Alemà GS, Morley-Fletcher S et al (2008). Prenatal restraint stress generates two distinct behavioral and neurochemical profiles in male and female rats. PLoS One 3: e2170. 